\title{
Impact of B203 on Physical, Optical Characteristics and Radiation Attenuation Factors of Borotellurite Glasses
}

\section{R. El-Mallawany}

Menoufia University

Weam aboutaleb ( $\nabla$ aboutalebw@alexu.edu.eg )

Alexandria University

\section{M.A. Naeem}

Alexandria University

\section{S.M. Kotb}

Alexandria University

\section{M.E. Krar}

Alexandria University

\section{S. Talaat}

Alexandria University

\section{Research Article}

Keywords: Glasses, Optical properties, Radiation shielding, MCNP5 code, XCOM software

Posted Date: January 7th, 2022

DOI: https://doi.org/10.21203/rs.3.rs-1231390/v1

License: (1) This work is licensed under a Creative Commons Attribution 4.0 International License.

Read Full License

Version of Record: A version of this preprint was published at Journal of Materials Research and Technology on March 1st, 2022. See the published version at https://doi.org/10.1016/j.jmrt.2022.03.107. 


\section{Impact of $\mathrm{B}_{2} \mathrm{O}_{3}$ on physical, optical characteristics and radiation attenuation factors of borotellurite glasses}

R. El-Mallawany a,, W.M. Abou-Taleb b* ${ }^{\text {a }}$ M.A. Naeem ${ }^{c}$, S.M. Kotb ${ }^{\text {b }}$, M.E. Krar ${ }^{\text {c }}$, S. Talaat b

aPhysics Department, Faculty of Science, Menoufia University, Shebin El-Koom, 32511, Menoufia, Egypt

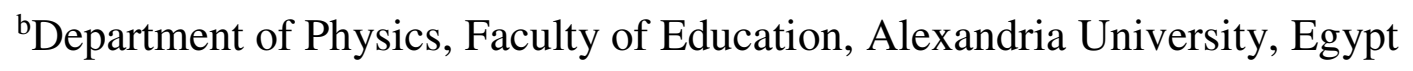

${ }^{\mathrm{c} D e p a r t m e n t ~ o f ~ P h y s i c s, ~ F a c u l t y ~ o f ~ S c i e n c e, ~ A l e x a n d r i a ~ U n i v e r s i t y, ~ E g y p t ~}$

* Corresponding author: aboutalebw@alexu.edu.eg

\section{Abstract:}

Borotellurite glasses with a composition $\left[(60-\mathrm{X}) \mathrm{TeO}_{2}-(20+\mathrm{X}) \mathrm{B}_{2} \mathrm{O}_{3}-10 \mathrm{Li}_{2} \mathrm{O}-10 \mathrm{Bi}_{2} \mathrm{O}_{3}\right]$ where $x=5-20$ in steps of $5 \mathrm{~mol} \%$ have been synthesized. Glass density, molar volume, oxygen packing density, and many other physical parameters were measured. UV-spectra in the wave length range (200-800) nm have been measured for the whole glass series. The optical energy band gap $E_{\mathrm{opt}}$, refractive index, and optical basicity were measured. The mass absorption coefficients $\left(\mu_{\mathrm{m}}\right)$ are determined experimentally by the HPGe detector and compared with the theoretical values obtained by XCOM program and MCNP5 simulation code within (0.121-1.408) $\mathrm{MeV}$ photon energy range. Half value layer (HVL), effective atomic number and electron density ( $\mathrm{Z}_{\mathrm{eff}}$ and $\left.\mathrm{N}_{\mathrm{eff}}\right)$, and macroscopic removal cross-section $\left(\sum \mathrm{R}\right)$ were evaluated. The sample $\left[55 \mathrm{TeO}_{2}-25 \mathrm{~B}_{2} \mathrm{O}_{3}-10 \mathrm{Bi}_{2} \mathrm{O}_{3}-10 \mathrm{Li}_{2} \mathrm{O}\right]$ possess the highest values of $\left(\mu_{\mathrm{m}}=1.192 \pm 0.033 \mathrm{~cm}^{2} / \mathrm{g}, \mathrm{Z}_{\mathrm{eff}}=56.12 \mathrm{e} /\right.$ atom and $\left.\sum \mathrm{R}=0.101499 \mathrm{~cm}^{-1}\right)$ at energy $121 \mathrm{keV}$ also lower values of $(\mathrm{HVL}=0.121 \mathrm{~cm}, \mathrm{TVL}=0.1 \mathrm{~cm}$ and $\mathrm{MFP}=0.174$ $\mathrm{cm}$ ) at photon energy $121 \mathrm{keV}$, therefore this sample considered the best gamma ray shielding material among the prepared glasses.

Keywords: Glasses; Optical properties; Radiation shielding; MCNP5 code; XCOM software.

\section{Introduction:}

Tellurite glasses have been created in binary, ternary, and quaternary forms since the early 1980s and have been examined as an excellent example of the new non-crystalline solids. For nearly four decades, research has focused on the development of new materials by modifying $\mathrm{TeO}_{2}$ glass with rare earth (R.E.) or transition metal (TM) ions to obtain 
interesting optical, electrical, thermal, and elastic properties; in addition, research articles about the structure of tellurite glasses have been published [1-10]

Today's the need for a shield to reduce harmful effects associated with a radiation dose is the only way, so the need to a transparent shield has become important especially in nuclear research laboratories, medicine (radio therapy), nuclear reactor (fission from 1 to 2 $\mathrm{MeV}$ ) and agricultural in order to watch what happening inside the laboratory and monitor everything through it without the need to be exposed to harmful radiation that may cause serious damage that is difficult to repair. The most popular (concrete and lead); have some of disadvantages such as toxicity, opaque and poor product qualities. Glasses were examined among these materials by different researchers in the last several years with regard to purity and high absorption of radiation [11-15]. In general, (phosphorous, silicon, and boron) oxides are considered glass-formers. $\mathrm{B}_{2} \mathrm{O}_{3^{-}}$based glasses have gained popularity among the investigators and scientists because $\mathrm{B}_{2} \mathrm{O}_{3}$ - based glasses are relatively cheap, have good transparency and are compatible with the needed forms and dimensions. [16].

The principle purpose of this work to examine the optical and gamma protection characteristics of the present fabricated glasses $\left[(60-\mathrm{X}) \mathrm{TeO}_{2-}(20+\mathrm{X}) \mathrm{B}_{2} \mathrm{O}_{3}-10 \mathrm{Li}_{2} \mathrm{O}-\right.$ $10 \mathrm{Bi}_{2} \mathrm{O}_{3}$ ]. The following items were carried out to achieve these goals:

1- $\mathrm{TeO}_{2}-\mathrm{B}_{2} \mathrm{O}_{3}-\mathrm{Li}_{2} \mathrm{O}-\mathrm{Bi}_{2} \mathrm{O}_{3}$ glasses were prepared.

2- Many factors were measured in the structure of the synthesized glass.

3- UV measurements were carried out of the prepared glasses.

4- Many Optical features were estimated.

5- The mass absorption coefficient and many other related parameters were evaluated for the present fabricated glass samples experimentally and theoretically by using two programs (MCNP5 simulation code and XCOM).

\section{Materials and method}

\subsection{Glass preparation}

All glasses were prepared from pure chemicals (powder). Telliurium oxide $\mathrm{TeO}_{2}$, lithium oxide $\mathrm{Li}_{2} \mathrm{O}$ as lithium carbonate $\mathrm{Li}_{2} \mathrm{CO}_{3}$, boron oxide $\mathrm{B}_{2} \mathrm{O}_{3}$, and bismuth oxide $\mathrm{Bi}_{2} \mathrm{O}_{3}$ were used in the this study. The amounts of the initial materials were weighted for each specimen depend on the equation $\left[(60-\mathrm{X}) \mathrm{TeO}_{2-}\right.$ 
$\left.(20+\mathrm{X}) \mathrm{B}_{2} \mathrm{O}_{3}-10 \mathrm{Li}_{2} \mathrm{O}-10 \mathrm{Bi}_{2} \mathrm{O}_{3}\right]$ where $\mathrm{x}$ from $(5-20) \mathrm{mol} \%$ by step 5 , these glasses are up to (4.8248) ${\mathrm{g} . \mathrm{cm}^{-3}}$ high in density. To produce homogenous blends, a mortar used for 10 minutes. The powder was heated in crucible of alumina at 500 ${ }^{\circ} \mathrm{C}$ for half hour in a muffle furnace. Then melted in a muffle oven for $20 \mathrm{~min}$ its temperature was raised gradually from $(840-880){ }^{\circ} \mathrm{C}$. For perfect homogeneity, crucibles have frequently been shaken. The transparent melt pressed with a steel rod and cooled at room temperature. At $300{ }^{\circ} \mathrm{C}$ each specimen annealed for 12 hours to reduce the crack. The glasses are polished to ensure that the surface is parallel, smooth and clear.

\subsection{Physical properties}

The density ( $\rho$ ) of the studied glasses was calculated by using the law of Archimedes. Refined water was used as a dipping liquid. The $1^{\text {st }}$ measurements were made in air $\left(\mathrm{m}_{\mathrm{a}}\right), 2^{\text {nd }}$ in water $\left(\mathrm{m}_{\mathrm{w}}\right)$ of density $\rho_{w}=1 \mathrm{~g} \mathrm{~cm}^{-3}$. The density of the glass $\left(\rho_{g}\right)$ calculated using the equation:

$$
\rho_{g}=\left(\frac{m_{a}-m_{w w}}{m_{a}}\right) \rho_{w}
$$

The molar volume $\left(\mathrm{V}_{\mathrm{m}}\right)$ of the present samples was deduced by:

$$
\mathrm{V}_{\mathrm{m}}=\frac{M_{w t}}{\rho}
$$

Where $\mathrm{M}_{\mathrm{wt}}$ the molecular weight for all specimens were estimated from [5]:

$$
\mathrm{M}_{\mathrm{wt}}=\sum \mathrm{m}_{\mathrm{k}} \mathrm{Z}_{\mathrm{k}}
$$

Where $m_{k}$ the ratio oxide component by mole.

$Z_{k}$ each single oxide's molecular weight.

Oxygen packing density (OPD) is the arrangement of oxygen atoms of the glass system can be obtained as below,

$$
O P D=1000 \times C \times \frac{\rho_{g}}{M_{w t}}
$$

Where $\mathrm{C}$ is the number of oxygens per formula unit.

Concentration of ions $\left(\mathrm{N}_{\mathrm{i}}\right)$ (ions $\left./ \mathrm{cm}^{3}\right)$ of the fabricated glasses is given by Eq. (5) [17].

$$
\mathrm{N}_{\mathrm{i}}=\frac{\mathrm{B}_{2} \mathrm{O}_{3} m o l \% * \rho * N_{A}}{\mathrm{~V}_{\mathrm{m}}}
$$

Where $\mathrm{N}_{\mathrm{A}}$ Avogadro's number. 
Using the values of ion concentrations, Polaron radius $\left(r_{p}\right)$ and Inter-nuclear distance $\left(\mathrm{r}_{\mathrm{i}}\right)$ were calculated [17].

$$
\begin{gathered}
r_{p}=\frac{1}{2}\left(\frac{\Pi}{6 N}\right)^{1 / 3} \\
r_{i}=\left(\frac{1}{N}\right)^{1 / 3}
\end{gathered}
$$

Which is the $\left(r_{i}\right)$ the inter ionic distance between the two (B) ions.

The optical absorption spectrum of the finely shaped glass components about $\sim 3 \mathrm{~mm}$ thickness were measured at room temperature using the double-beam spectrophotometer Perkin-Elmer 402 within wavelength range (200-800) nm.

\subsection{Optical properties}

In this work, the optical energy band gap $\left(\mathrm{E}_{\mathrm{opt}}\right)$ was studied using two methods: Tauc's method and absorbance spectrum fitting (ASF) method). In the first method, Lambert - Beer - Bouguer law was used to calculate the optical energy band gaps for our glasses [18] via the absorption spectrum used.

$$
\alpha(v)=\left(\frac{1}{t}\right) \ln \left(\frac{I_{i}}{I_{t}}\right)=\frac{2.303 \mathrm{~A}}{t}
$$

Where $\alpha(v)$ the absorption of UV of the amorphous substance, $\left(I_{i}\right)$ the incident intensity, $\left(I_{t}\right)$ the transmitted intensity, $(A)$ the absorbance of light and $(\mathrm{t})$ is the thickness of each specimen. Eq. (8) has been generated by Tauc [18], then Mott and Davis [19] as:

$$
\alpha h v=B\left(h v-E_{o p t}\right)^{s}
$$

The incident gamma ray energy $(h v=E)$, (B) is a constant and $S$ $=0.5$ and 2 for direct and indirect transition respectively. Plots of $(\alpha E)^{2}$ and $(\alpha E)^{1 / 2}$ versus (E) were drawn for all samples, values of $\left(E_{\text {opt }}\right)_{\text {Tauc's }}$ calculated, where $(\alpha E)^{2}$ and $(\alpha E)^{1 / 2}=0$ [21].

In the (ASF) method, the optical band gaps directly mainly with the following equation by utilizing the absorption data, without the need for thickness of glass [21]:

$$
\mathrm{E}_{\mathrm{ASF}}=\frac{h c}{\lambda_{\text {(cut }- \text { off })}}=\frac{1239.83}{\lambda_{(\text {cut }- \text { off })}}
$$

Where the planck's constant, light velocity and (cut-off) wavelength are

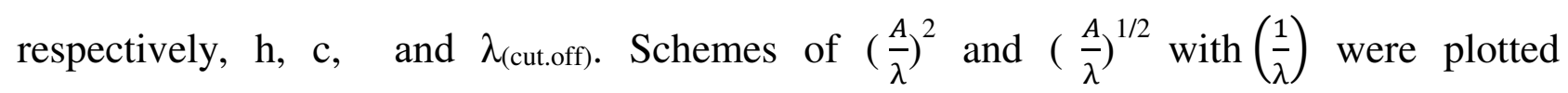
for all glasses. 
Urbach's energy $(\Delta E)$ for amorphous compound disarray evaluation; Urbach's lower energy values show a lower glass existence, estimated by the slope of plotting line $\ln (\alpha)$ against (hv), in accordance with the empirical law of Urbach [21]:

$$
\ln \alpha=\ln \alpha_{O}+\left(\frac{h v}{\Delta E}\right)
$$

The linear refractive index $(n)$ was calculated for all samples using $\left(E_{o p t}\right)$ values [21]:

$$
\frac{n^{2}-1}{n^{2}+1}=1-\sqrt{\frac{E_{o p t}}{20}}
$$

The molar refractivity $\left(R_{m}\right)$, molar polarizability $\left(\propto_{m}\right)$ and reflection loss $\left(\mathrm{R}_{\mathrm{L}}\right)$ of the investigated glasses were estimated by [22]:

$$
\begin{gathered}
R_{\mathrm{m}}=\left(\frac{n^{2}-1}{n^{2}+1}\right) \\
\propto_{m}=\left(\frac{3}{4 \pi \mathrm{N}}\right) R_{m} \\
\mathrm{R}_{\mathrm{L}}=\left(\frac{\mathrm{R}_{\mathrm{m}}}{\mathrm{V}_{\mathrm{m}}}\right)
\end{gathered}
$$

Depending on the metallization (M) values, the material kind (metallic or Insulator) [22]:

$$
\mathrm{M}=1-\left(\frac{\mathrm{R}_{\mathrm{m}}}{\mathrm{v}_{\mathrm{m}}}\right)
$$

In addition, dielectric constants (static and optical) are estimated by the refractive index [22]:

$$
\varepsilon^{\text {static }}=\mathrm{n}^{2} \quad \text { and } \quad \varepsilon^{\text {optical }}=\mathrm{n}^{2}-1
$$

The electro-negativity $(\chi)$ of the studied glasses was determined by using $\left(\mathrm{E}_{\mathrm{opt}}\right)$ as follow:

$$
\chi=0.2688 E_{\mathrm{opt}}
$$

Finally, the electro-polarizability $\left(\propto^{\circ}\right)$ and optical basicity $(\Lambda)$ values have been computed by [22]:

$$
\begin{gathered}
\propto^{\circ}=-0.9 \chi+3.5 \\
\wedge=-0.5 \chi+1.7
\end{gathered}
$$

\subsection{Gamma interaction with matter}


As known photon can interact with matter via three processes photoelectric absorption (PE), Compton scattering (CS), and Pair production (PP). The total attenuation coefficient $\left(\mu_{\mathrm{m}}\right)$ for photon from the three physical process $\left(\mu_{\mathrm{total}}=\mu_{\mathrm{PE}}+\mu_{\mathrm{CS}}+\mu_{\mathrm{PP}}\right)[23]$. The degree of attenuation depends on the dispersion and several absorption processes. The gamma ray detector has been used to measure the mass attenuation coefficient, utilize by HPGe detector. It has the following specifications: i) the efficiency of the detector is $24.5 \%$ for $1.333 \mathrm{MeV}$, ii) the resolution is $2.2 \mathrm{keV}$ at $1.333 \mathrm{MeV}$, iii) the detector surrounded by a thick lead shield about $10 \mathrm{~cm}$, and is concentric with a Copper thin layer. (Genie 2000) Software is used to collect and analyze the gamma ray spectra. Both the gamma point source, and the Samples of glass have been housed and centered in a two collimators, lead shields with a very narrow hole in the center of the collimator, the upper cylinder (length $10 \mathrm{~cm}$ ) its diameter $=0.5 \mathrm{~cm}$ which is equal to the diameter of the point source and the lower one (length $10 \mathrm{~cm}$ ) its diameter $=1 \mathrm{~cm}$. The source was at the top of the upper cylinder and it's covered with a lead cap, the glass samples placed at the end of the upper one in its cavity to ensure that it does not move during the measurements. All the lead system was placed inside the head of crystal by using a stand of wood. The reason to use two collimators to generate a narrow beam to minimized the systematical errors. ${ }^{152} \mathrm{Eu}$ point source with strength $(290 \pm 4) \mathrm{kBq}$ emitting gamma ray photons with energies $(0.121$, $0.344,0.778,0.964,1.112$ and 1.408$) \mathrm{MeV}$ their emission abundance probabilities (28.37, $26.57,12.97,14.63,13.54$ and 20.85) \% respectively which represented in Fig. 1a.

The intensity of gamma ray $\left(\mathrm{I}_{0}\right.$ and $\left.\mathrm{I}\right)$ were measured by putting the glass specimen between the source and the crystal detector. The measured time was set to $3600 \mathrm{sec}$, the back ground radiation intensity was also measured for the same time and subtracted from each of the readings.

$$
\begin{gathered}
\mathrm{I}=\mathrm{I}_{0} \mathrm{e}^{-\mu_{l} \mathrm{x}} \\
\mu_{m}=\ln \left(I_{o} / I\right) / \rho x
\end{gathered}
$$

Where $\mu_{m}$ the mass absorption coefficient and $\mathrm{x}$ is the glass thickness (cm) which lies between $(0.185$ to 0.285$) \mathrm{cm}$.

The mass absorption coefficient $\left(\mu_{\mathrm{m}}\right)\left(\mathrm{cm}^{2} / \mathrm{g}\right)$ of the studied glasses was estimated theoretically by a mixture rule $[11,12]$ :

$$
\left(\mu_{\mathrm{m}}\right)_{\mathrm{glass}}=\Sigma_{\mathrm{i}} W_{\mathrm{i}}\left(\mu_{\mathrm{m}}\right)_{\mathrm{i}}
$$


Where $\left(w_{\mathrm{j}}\right)$ and $\left(\mu_{\mathrm{m}}\right)_{\mathrm{i}}$ are weight fraction and mass absorption coefficient in the sequence of samples of the investigated element.

Also basic factors, half value layer (HVL) and tenth value layer (TVL) which define as, the thickness of the shield that reduces the initial intensity ( $\left.I_{0}\right)$ by $50 \%$ and $10 \%$ respectively[11,12].

$$
\begin{aligned}
& \mathrm{HVL}=0.693 / \mu_{l} \\
& \mathrm{TVL}=2.302 / \mu_{l}
\end{aligned}
$$

Where $\mu_{l}$ is the linear absorption coefficient ( $\mathrm{I}=\mathrm{I}_{0} \mathrm{e}^{-\mu_{l} \mathrm{x}}$ )

The mean free path (MFP) of glasses which indicates to the average interval between two successive photon interactions can be calculated as [22]:

$$
\operatorname{MFP}=\left(\mu_{l}\right)^{-1}
$$

The effective atomic number $\left(\mathrm{Z}_{\mathrm{eff}}\right)$ and the effective ion density $\left(\mathrm{N}_{\mathrm{eff}}\right)$ were estimated from [22]:

$$
\begin{aligned}
& \mathrm{Z}_{\text {eff }}=\frac{\sum_{i} f_{i} A_{i}\left(\mu_{m}\right)_{\mathrm{i}}}{\sum_{i} \frac{A_{i}}{Z_{i}}\left(\mu_{m}\right)_{\mathrm{i}}} \\
& \mathrm{N}_{\text {eff }}=\frac{N_{A}}{A_{m}} Z_{\text {eff }} \sum_{i} n_{i}
\end{aligned}
$$

Where $\sum_{i} n_{i}$ total number of sample elements and $\mathrm{A}_{\mathrm{m}}$ the glass atomic mass.

Using the mass removal cross section, the bioactive glass systems were assessed $(\Sigma R / \rho)$ values of the elements in the shield material by using [22]:

$$
\Sigma \mathrm{R}=\Sigma \mathrm{W}_{\mathrm{i}}(\Sigma \mathrm{R} / \rho)_{\mathrm{i}}
$$

Where $\mathrm{W}_{\mathrm{i}}$ is the partial density $\left(\mathrm{W}_{\mathrm{i}}=\mathrm{W}_{\mathrm{i}} \rho_{\mathrm{s}}\right)$ where $\mathrm{w}_{\mathrm{i}}$ is the fraction by weight of the $\mathrm{i}$ component and $\rho_{\mathrm{s}}$ is the sample density. To investigate the radiation shielding ability of prepared glass samples, the $\left(\mu_{\mathrm{m}}\right)$ values have been estimated experimentally using HPGe detector as in Fig.1 a, theoretically by XCOM [24,25] and MCNP5 simulation code [25, 26] as in Fig. 1 b.

\section{Results and discussion}

The density of the glass is usually considered an important parameter, because any change in the density of a glass indicates the change in the chemical composition and in the glass structure from Table 1. It can be shown that the density of a glass samples decreases while the molar volume is increases with the decrease in $\mathrm{TeO}_{2}$ from (55 to 40) $\mathrm{mol} \%$ 
content also increase in the $\mathrm{B}_{2} \mathrm{O}_{3}$ from (25 to 40) mol\% content. This is can be attributed to the replacement of higher atomic weight of $\mathrm{TeO}_{2}(159.59 \mathrm{~g} / \mathrm{mol})$ by lighter atomic weight $\mathrm{B}_{2} \mathrm{O}_{3}(69.62 \mathrm{~g} / \mathrm{mol})$ content, so we can say there is a strong relation between the density and the glass structure [17]. From Table 1, the addition of $\mathrm{B}_{2} \mathrm{O}_{3}$ mol\% content in the glasses decreases the compactness of the glass network. The large radius of $\mathrm{B}_{2} \mathrm{O}_{3}$ than $\mathrm{TeO}_{2}$ increases the molar volume. The measured molar volume values showed an increasing trend, these mean that the molar volume and density are inversely proportion to each other as [28]. In the prepared glass specimens the decrease in the density is expected because the heavier oxide $\left(\mathrm{TeO}_{2}\right)$ was replaced by the lighter one $\left(\mathrm{B}_{2} \mathrm{O}_{3}\right)$ which decrease the all molecular weight of the glass which is represented in Table 2. The molecular weight values ranged from (154.77 to 141.27$) \mathrm{g} / \mathrm{mol}$. The increase in molar volume as a result of the formation of NBO (non- bridging oxygen) which caused an opening structure by shattering the bonds, increasing in free volume, as shown in [27] the Tellurium oxide replaced by Boron oxide. The OPD (oxygen packing density) increased from (70.14 to 73.78 ) mol/L by raising the boron oxide content from ( 25 to 40 ) mol\% content because of increased the oxygen atom number per unit composition from (2.25 to 2.4) oxygen atom fraction. This behavior is attributed to the fraction of oxygen atom when tellurium oxide replaced by boron oxide is equal (3: 2) respectively which agreement with research [28]. Other physical parameters such as the ion concentration $B_{\text {ions }}\left(\mathrm{N}_{\mathrm{i}}\right)$ are increased with increase the concentration of $\mathrm{B}_{2} \mathrm{O}_{3}$ values according to Table 2, polaron radius $\left(r_{p}\right)$ and inter- nuclear distance $\left(r_{i}\right)$ are estimated by using Eqs. (5-7). It shown that the values of $r_{p}$ and $r_{i}$ varies with the addition of boron oxide content in the glasses. The value of of $r_{p}$ decrease with the increase of $\mathrm{B}_{2} \mathrm{O}_{3}$ mol\% into glass, which mean that the average space of $\mathrm{B}-\mathrm{B}$ or $\mathrm{r}_{i}$ shows decrease trend, the $r_{p}$ of each glass specimen smaller than the B-B spacing there is a good agreement with the polaron theory, that the $r_{i}$ must be greater than the $r_{p}$ on which the electron localized as seen in the study estimated by [29].

With increased $\mathrm{B}_{2} \mathrm{O}_{3}$ mol\% the absorption edge shifts to higher wavelengths Fig.3. The $\mathrm{E}_{\mathrm{Opt}}$ is the change of energy among conduction and valence bands of the glass when the energy of an incident light greater than the energy band gap the transition will occur [28]. The optical energy band gap calculated by Tauc's method by Eq. (9) for direct $\left(\mathrm{E}_{\mathrm{opt}}\right)_{\text {Tauc's }}$ of glasses as shown in Fig. 4a, which varied between (2.8975 to 2.7312$) \mathrm{eV}$ deduced in Table 3. Fig. 
$4 \mathrm{~b}$ represents the values of indirect ( $\left.\mathrm{E}_{\mathrm{Opt}}\right)_{\text {Tauc's }}$ of the glass samples changed between ( 2.6842 to 2.4571 ) eV when boron content increase. There is a decrease in $\mathrm{E}_{\mathrm{opt}}$ with rising in boron content which it's attributed to the formation of (NBO) as discussed before, also an increase of the disorder and increase in the nature of amorphous of the glass samples. The energy needed to excited the electron in the case of the (NBO) is smaller than the (bridging oxygen), which facilitates to shift the valence band to the conduction band which in turn decreases the optical energy band gap as studied [28]. Calculations of $E_{\text {opt }}$ from Eq. (10) which represented in Figs. (5a and 5b), showed that the direct $\left(E_{o p t}\right)_{\mathrm{ASF}}$ of the glass samples have high values (2.8875) $\mathrm{eV}$, but have value (2.7234) eV for indirect transition as the $\mathrm{B}_{2} \mathrm{O}_{3}$ mol\% content increases. The observations of $\left(\mathrm{E}_{\mathrm{opt}}\right)$ values realized by two techniques have been confirmed at Table 3 .

By using Eq. (12), the calculated values of the refractive index which represented at Table 3. The values of ( $n$ ) estimated by two methods for direct and indirect transitions increasing with the increase of boron oxide mol\% content. This is due to the high polarity of the third boron ion $\left(\mathrm{B}^{3+}\right)$ which break (bridging oxygen $(\mathrm{BO})$ ) to form (non- bridging oxygen (NBO)) which have high polarity, so (NBO) affected on the value of the refractive index. These synthesized glass samples are characterized by its high refractive index by compare with glasses studied by [15, 29]. An Urbach energy: the measure of disorder of the glasses and calculated by Eq. (11). This represented at Table 2. The increasing in the $\mathrm{B}_{2} \mathrm{O}_{3}$ from (25 to 40) mol\% content, the values of Urbach energy increased from (0.263 - 0.327) eV which it means that the disorder of boron samples increased, with increased the defect in the glass samples and forming the (NBO) [28, 29].

The $\mathrm{R}_{\mathrm{m}}$ values increases from 26.624 to $27.209\left(\mathrm{~cm}^{3} \cdot \mathrm{mol}^{-1}\right)$ with increasing of $\mathrm{B}_{2} \mathrm{O}_{3} \mathrm{~mol} \%$ as shown in Table 2 . The $\mathrm{R}_{\mathrm{m}}$ is correlated to the molar polarizability of a material $\left(\propto_{\mathrm{m}}\right)$ as deduced by Eq. (14). The resultant values of $\left(\propto_{\mathrm{m}}\right)$ increase from $10.559 \times 10^{-24}$ to 10.792 $\times 10^{-24}\left(\mathrm{~cm}^{3} \cdot \mathrm{mol}^{-1}\right)$ with increasing $\mathrm{B}_{2} \mathrm{O}_{3} \mathrm{~mol} \%$ as tabulated in Table 2. Accordingly, increasing the $\mathrm{R}_{\mathrm{m}}$ is in direct relation with increases the glass polarizability which agreement with research [30].

Metallization of the glass specimen is used to know the nature of the solid based on the values of refractive index to deduce the nature of the solid and depend on the reflection loss 
$\left(R_{L}\right)$ with using Eq. (16). The rule of thumb being used is $\left(\mathrm{R}_{\mathrm{m}} / \mathrm{V}_{\mathrm{m}}\right)<1$ (is non- metallic ) and if $\left(R_{m} / V_{m}\right)>1$ (is a metallic). In this study the decrease of calculated values of metallization ranged from $(0.170-0.163)$ which indicates that the type of the synthesis glass is non- metallic which represented in Table 2.

The dielectric constants ( $\mathcal{E}^{\text {static }}, \mathcal{E}^{\text {optical }}$ ) calculated by Eq. (17) are exactly proportionate to each other but reverse with a metallization characteristic (M) that is good agreement with work [22].

The electro-polarizability is a parameter used to specified the nature of the bonds present in the solid and calculate it. As summarized in Table 2. When the boron oxide mol\% increase the polarizability of increased from (2.799 to 2.839) this can be due to the breaking of Te-O-Te bond when $\mathrm{B}$ ions is injected into the network and produce a nonbridging oxygen. So that NBO possess high polarizability values. The values of electronegativity $(\chi)$ which calculated by Eq. (18) based on $\left(E_{o p t}\right)$ see Table 2. The electro polarizability $\left(\propto^{\circ}\right)$ displayed at Fig. 9, optical basicity $(\Lambda)$ at Fig. 10 were calculated by Eqs. (19 and 20) respectively. With increasing the $\mathrm{B}_{2} \mathrm{O}_{3} \operatorname{mol} \%,\left(\propto^{\circ}\right)$ and $(\Lambda)$ values are increased. The strongly polarizable of $\mathrm{B}_{2} \mathrm{O}_{3}$ relative to $\mathrm{TeO}_{2}$ leads to enhanced in optical basicity $(\Lambda)$.

Optical basicity values ranged from (1.311 to 1.333 ) see Table 2 . With the boron oxide content increase, this shows that the polarizability of the glass samples increases as shown for refractive index. This increase in polarizability showed that there is an increase in NBO content.

The experimental results of the mass attenuation coefficient $\mu_{\mathrm{m}}$ showed in Table 4 for boron concentrations ranged from (25 to 40) mol\% contents calculated experimentally by HPGe detector with the aid of Eq. (22) which compare with values estimated theoretically using MCNP5 simulation code and XCOM programs throughout $(0.121,0.343,0.778$, $0.964,1.112$ and 1.408$) \mathrm{MeV}$ photon energy. Perfect agreement within $\mu_{\mathrm{m}}$ obtained from the experimental data and the values obtained from MCNP5 code. According to this performance, Fig. 11, which represent the behavior of mass attenuation coefficient obtained by the three methods and compare between them for all concentration of $\mathrm{B}_{2} \mathrm{O}_{3}$, significant declines in $\left(\mu_{\mathrm{m}}\right)$ with increasing the photon energy from (0.121 to 1.408$) \mathrm{MeV}$. The values obtained from XCOM program differ from the EXP and MCNP5 code, this may be attributed to the weakness of the XCOM program, which it doesn't take into account the 
shape, thickness of the sample, type of the detector also the geometry of the system, so these are a clear defects in that program. Fig. 12 shows that the mass attenuation coefficient of different boron mol\% content and their variations with gamma ray energies. It is clear that all the samples have nearly the same behavior; it is obvious that the $\mu_{\mathrm{m}}$ values of all glass samples dramatically decrease with the increase of photon energy from (121 to 343) $\mathrm{keV}$ (photoelectric process (PE)) is the dominant mechanism at low energy as $\left(\sigma_{\mathrm{PE}}\right)$ proportion with $\mathrm{E}^{-7 / 2}$. Then slightly decrease of $\left(\mu_{\mathrm{m}}\right)$ with the increasing of the photon energy. But From (778 to 964) $\mathrm{keV}$ there is no significant decrease in $\mu_{\mathrm{m}}$ values with gamma energy and the values are approximately constant for all samples due to Compton scattering (CS) the more influenced interaction, cross -section $\left(\sigma_{\mathrm{CS}}\right)$ is proportional to the energy of photons $\mathrm{E}^{-1}$. Up to $\sim 1020 \mathrm{keV}$ the mass attenuation slightly increase but still approximately constant for all glasses, this behavior of the attenuation with gamma energy may be attributed to pair production (PP), $\mu_{\mathrm{m}}$ values are decrease with increasing energy due to cross section $\left(\sigma_{\mathrm{pp}}\right)$ directly proportion with energy $\mathrm{E}$ in the third region from (1112 to 1408$) \mathrm{keV}$ slightly with the effect from Compton Scattering which decreases.

From the above results it have been concluded that the higher probability of photon interaction with glass samples occurs in the lower photon energy. From Table 4 the gamma radiation attenuation don't change with addition of $\mathrm{B}_{2} \mathrm{O}_{3}$ mol\% content in the synthesized glasses from (25 to 40) mol\% content. Thus the power of the complex materials can be concluded as follow: Bi (heavy element) is the main element for shielding gamma ray using in this work have a small influence on the shielding properties against gamma ray because its content in all samples is constant $(\mathrm{Bi}=10 \mathrm{~mol} \%)$, but boron which varying in these glasses not sufficient to affected on the gamma shielding, therefore there is no change in $\mu_{\mathrm{m}}$ values, the reason to use B in our prepared glasses, B act as a glass former. We can note that it can be used as a good neutron shield (light element). Finally the perfect boron sample in gamma shielding is the sample $\left(55 \mathrm{TeO}_{2}, 25 \mathrm{~B}_{2} \mathrm{O}_{3}, 10 \mathrm{Bi}_{2} \mathrm{O}_{3}\right.$ and $\left.10 \mathrm{Li}_{2} \mathrm{O}\right) \mathrm{mol} \%$ content which possess the high density $(4.8248) \mathrm{g} / \mathrm{cm}^{3}$

The variance in the experimental values of $\mathrm{HVL}$ of our prepared glasses $\left(\mathrm{TeO}_{2}-\mathrm{B}_{2} \mathrm{O}_{3}\right.$ $-\mathrm{Bi}_{2} \mathrm{O}_{3}-\mathrm{Li}_{2} \mathrm{O}$ ) with different percentage (mol\%) have been calculated by Eq. (24) with the help of $\mu_{\mathrm{m}}$ values Fig. 13 shows that the minimum values for HVL was found at photons with low energy this attributed to the main affected interaction is photoelectric effect (PE) dominance (due to there is no effect from low $\mathrm{Z}$ of Boron 
according to $\left.\left(\sigma_{\mathrm{PE}} \alpha \frac{z^{5}}{E^{7 / 2}}\right)\right)$. Increased gradually with the increase of photon energy (> 0.5 to 0.964$) \mathrm{MeV}$ the PE probability decrease and Compton scattering probability increased where $\left(\sigma_{\mathrm{CS}} \alpha \frac{1}{E}\right)$. At energy Zone up to $1.02 \mathrm{MeV}$ there is a significant increase in HVL values due to the dominant interaction in this zone is pair production where ( $\sigma_{\mathrm{PP}} \alpha$ E ) which mean that pair production interaction its probability increase with photon energy. For all samples selected, a fast increase in HVL with photon energy, have maximum value at $1.408 \mathrm{MeV}$ for all samples attributed to the ( $\left.\sigma_{\mathrm{PP}}>\sigma_{\mathrm{CS}}\right)$ and Compton scattering decrease; Also from Fig. 13, the sample (B 25 and Te 55) mol\% content possess the lower HVL $(0.121 \mathrm{~cm})$ at energy $121 \mathrm{keV}$ and $(2.9 \mathrm{~cm})$ at energy 1408 $\mathrm{keV}$, its lower values represented that shield is more effective between our prepared glasses. The HVL for B25 is less than all the glasses tested by [31, 32].

The TVL and MFP have the same behavior as HVL, these values calculated by using Eqs. 25 and 26 with the variation of $\mathrm{B}_{2} \mathrm{O}_{3}$ from (25 to 40 ) mol\% content at the selection energy as shown in Figs. 14 and 15. The experimental values of these parameters are various with photon energy from (121 to 1408) $\mathrm{keV}$, from TVL and MFP figures, it is obvious from these curves there are a dramatically increase with photon energy, at energy zone from (121 to 343$) \mathrm{keV}$ these parameters have the smallest values due to the main interaction affectd in this is (photoelectric process), which its probability inversely proportion with energy by $E^{-3.5}$. With increasing the photon energy the values of these parameters increases which attributed to the (Compton scattering) is dominant interaction. At energy up to $1.02 \mathrm{MeV}$ there is a rapid increase in these values with energy for all glasses due to the pair production is dominant interaction. Also, Figs. 14 and 15 showed that sample ( $25 \mathrm{~B}_{2} \mathrm{O}_{3}$ and $55 \mathrm{TeO}_{2}$ ) mol\% content possess the lower TVL ( 0.4 and 9.64) $\mathrm{cm}$ at energies (121 and 1408) keV respectively, for MFP (0.174 and 4.19) $\mathrm{cm}$ at energies (121 and 1408) $\mathrm{keV}$ respectively. The reduction in these parameters with energy is the good ability of these shields to attenuate primary radiation.

The $Z_{\text {eff }}$ values of the investigated samples are estimated by using Eq. (27), the variation of $Z_{\text {eff }}$ for the prepared glasses with energy is displayed in Fig. 16, which represented the effective atomic number $Z_{\text {eff }}$ of all glasses with photon energy. The values of $Z_{\text {eff }}$ of the fabricated glasses decreases with the replacement of $\left(\mathrm{TeO}_{2}\right.$ by $\left.\mathrm{B}_{2} \mathrm{O}_{3}\right)$ see Fig. 16, the values of $\mathrm{Z}_{\mathrm{eff}}$ is 56.12 (e/atom) at $121 \mathrm{keV}$ and 
19.24 (e /atom) at energy $1408 \mathrm{keV}$ for glass sample (B25) as seen in Table 1, which displayed the values of $\mathrm{Z}_{\mathrm{eff}}$ is 54.87 (e/atom) at $121 \mathrm{keV}$ and 16.5 (e/atom) at energy $1408 \mathrm{keV}$ for glass sample (B40). A rapid decrease in the value of $Z_{\text {eff }}$ after $0.1 \mathrm{MeV}$, because the photoelectric dependent on photon energy as $\mathrm{E}^{-7 / 2}$, but $Z_{\mathrm{eff}}$ values are mainly constant up to $0.9 \mathrm{MeV}$ where the controlling interaction at this energy zone is Compton scattering, while for energy $(1.02 \mathrm{MeV}<\mathrm{E}<1.2$ $\mathrm{MeV}) \mathrm{Z}_{\mathrm{eff}}$ values increases with gamma energy which due to dominant of (pair production) and the (Compton effect), then after that remarkable decreasing for $Z_{\text {eff }}$ curve can be showed with photon energy, the (Compton scattering) plays a neglected role. From Fig. 16 B25 is the best form of synthesized glasses in this high energy area for gamma shielding. This result also shows that a composition of glass has an important function in gamma protection.

The effective ion density calculated from the experimental results by using Eq. (28) for (B25, B30, B35 and B40) with the photon energy in the region (121 to 1408) $\mathrm{keV}$, represented in Fig. 17. One may observe that $\mathrm{N}_{\text {eff }}$ have the opposite relation with atomic mass $\left(\mathrm{A}_{\mathrm{m}}\right)\left(\mathrm{N}_{\text {eff }} \alpha \frac{1}{A_{m}}\right)$. Where $\mathrm{A}_{\mathrm{m}}$ for the glass samples varies from (41.53 for sample B20 to 35.32 for sample B40), so as we see the value of $A_{m}$ decrease with increasing the boron content, therefore values of $N_{\text {eff }}$ increase with boron content change from (25 to 40) mol\% .

The variation of $\mu_{\mathrm{m}}$ versus $\mathrm{B}_{2} \mathrm{O}_{3}$ mol\% content at energies from (121 to 1408) $\mathrm{keV}$ deduced in Fig. 18. The figure indicates that the B content not influenced on the values of $\mu_{\mathrm{m}}$ at higher energies greater than $(0.343 \mathrm{MeV})$, but on the other hand the $\mu_{\mathrm{m}}$ from experimental results have high values at low energy zone at (121 and 343 ) keV the main reason for that behavior can explained as follow:

1) At $\mathrm{E}=121 \mathrm{keV}$, the photoelectric absorption effect is the dominant interaction ( $\sigma_{\mathrm{PE}}$ $\left.\alpha \mathrm{E}^{-7 / 2}\right)$.

2) At $\mathrm{E}=343 \mathrm{keV}$, the effect of photoelectric is weak effect so that $\mu_{\mathrm{m}}$ have a slightly high values.

3) Up to $600 \mathrm{keV}$, there is no effect from PE but CS is the dominant interaction in the two lines (778 and 964) $\mathrm{keV}$, therefore there is a decrease in $\mu_{\mathrm{m}}$ for all glasses. 
4) Up to $1020 \mathrm{keV}$, at $\mathrm{E}=1112 \mathrm{keV}$ and $1408 \mathrm{keV}$, the effect of PP is clear and dominant and approximately constant also there is no effect for B content in these energies due to the small values of $\mathrm{M}_{\mathrm{wt}}$.

\section{The macroscopic effective removal cross section $(\Sigma R)$ :}

Using Eq. (29), the results are shown in Fig. 19 and listed in Table 5. It can be viewed from the figure that $\Sigma \mathrm{R}$ of the glass samples are quite near to each other and ranged from (0.101499 to 0.100936$) \mathrm{cm}^{-1}$ for samples ranged from (B25 to B40) mol\% content. The relatively high effective removal cross-section of sample (B25) sees Table 5. Can explained by its higher density $\left(4.8248 \mathrm{~g} / \mathrm{cm}^{3}\right)$ than the other samples (see Table 1 ), also can see that the sample (B40) which already has lower density $\left(4.3433 \mathrm{~g} / \mathrm{cm}^{3}\right)$ has lower $\Sigma \mathrm{R}$ value, therefore the results presented in Table 5 indicate that the density of the glass is an important parameter in neutron attenuation. As a result, it can be said that the sample (25 $\mathrm{B}_{2} \mathrm{O}_{3}, 55 \mathrm{TeO}_{2}, 10 \mathrm{Li}_{2} \mathrm{O}$ and $10 \mathrm{Bi}_{2} \mathrm{O}_{3}$ ) is the most appropriate sample among all prepared

glasses. It It was observed that the values of $\Sigma \mathrm{R}$ values of the present tellurite glasses were greater than $[34,35]$. In the future studies, we will take the Boron with low (mol\%) content ranging (15 to 30 ) and compare between them to find the best shield for neutrons.

\section{Conclusion}

Glass compositions $\left[(60-\mathrm{X}) \mathrm{TeO}_{2^{-}}(20+\mathrm{X}) \mathrm{B}_{2} \mathrm{O}_{3}-10 \mathrm{Li} 2 \mathrm{O}-10 \mathrm{Bi}_{2} \mathrm{O}_{3}\right]$, showed that:

- Density decreases from (4.8248 to 4.3433$) \mathrm{g} / \mathrm{cm}^{3}$ by increases the $\mathrm{B}_{2} \mathrm{O}_{3}$ due to the replacement of higher atomic weight of $\mathrm{TeO} 2(159.59 \mathrm{~g} / \mathrm{mol})$ by lighter atomic weight B2O3 (69.62 g/mol).

- Eopt reduces when $\mathrm{B} 2 \mathrm{O} 3 \mathrm{~mol} \%$ content rises due to the structural configuration which attributed to the formation of (NBO).

- Optical basicity values ranged from (1.311 to 1.333$)$ With the boron oxide content increase, this shows that the polarizability of the glass samples This increase in polarizability showed that there is an increase in NBO content.

- The maximum $\left(\mu_{\mathrm{m}}\right)$ values observed for sample B25 invistigated that to become a good absorber material against gamma radiation. With low photon energy $(<500 \mathrm{keV})$ the best attenuation for gamma occurs. 
- The value of $\mathrm{Z}_{\mathrm{eff}}$ of the prepared glasses decreases with the replacement of $\mathrm{TeO}_{2}$ by $\mathrm{B}_{2} \mathrm{O}_{3}$. Up to $1020 \mathrm{keV}$ it is a fast increase for $\mathrm{Z}_{\text {eff }}$ values due to $(\sigma \mathrm{CS}, \sigma \mathrm{PP})$ are dominant, at $1150 \mathrm{keV}$ due to $\mathrm{CS}$ is neglected and the PP process is the most affected interaction the $\mathrm{Z}_{\mathrm{eff}}$ decrease.

- The relatively high effective removal cross-section of sample (B25) is $0.101499 \mathrm{~cm}^{-1}$ can explained by its higher density $\left(4.8248 \mathrm{~g} / \mathrm{cm}^{3}\right)$ than the other samples.

Acknowledgement: The authors acknowledge Prof. Y. Rammah for his help.

\section{References:}

1. Ryogo Nakamori, Naoki Kawano, Akito Takaku, Daisuke Nakauchi, Hiromi Kimura, Masaki Akatsuka, Kenji Shinozaki, Takayuki Yanagida, Preparation and scintillation properties of the Eu3+-activated $\mathrm{SrO}-\mathrm{A} 12 \mathrm{O} 3-\mathrm{TeO} 2$ glasses, Materials Research Bulletin, $145,111547(2022)$

2. R El-Mallawany, AH El-Sayed, MMHA El-Gawad, ESR and electrical conductivity studies of (TeO2) 0.95 (CeO2) 0.05 semiconducting glasses, Materials chemistry and physics 41 (2), 87-91 (1995)

3. T. Han, X.-Y. Sun, X. Lai, (...), H. Guo, X. Ye, Role of Gd2O3 on tailoring structural and optical properties of Tb3+-activated borogermanate-tellurite glasses, Radiation Physics and Chemistry, 189,109734 (2021)

4. Pritha Patra, Kalyandurg Annapurna, Transparent tellurite glass-ceramics for photonics applications: A comprehensive review on crystalline phases and crystallization mechanisms ransparent tellurite glass-ceramics for photonics applications: A comprehensive review on crystalline phases and crystallization mechanisms, Progress in Materials Science 125 (2022) 100890

5. N. Effendy, H.A.A. Sidek, M.K. Halimah, M.H.M. Zaid, Enhancement on thermal, elastic and optical properties of new formulation tellurite glasses: Influence of $\mathrm{ZnO}$ as a glass modifier, Materials Chemistry and Physics, 273,125156 (2021)

6. R El-Mallawany, Structural and vibrational investigations of thermal properties of tellurite glasses, Journal of materials research 7 (1), 224-228 (1992) 
7. Raghvender, Assil Bouzid, DavidHamani, PhilippeThomas, Olivier Masson, A Buckingham interatomic potential for thallium oxide (T12O): Application to the case of thallium tellurite glasses, Computational Materials Science 201 (2022) 110891

8. R.El-Mallawany, Longitudinal elastic moduli of tellurite glasses, J.Applied Physics 73, 717 (1993)

9. M.C.Ersundu, A.E.Ersundu, N.S.Gedikoglu , E.Sakar, M.Büyükyıldız , M.Kurudirek, Physical, mechanical and gamma-ray shielding properties of highly transparent $\mathrm{ZnO}-\mathrm{MoO} 3-\mathrm{TeO} 2$ glasses. $\mathbf{J}$ Non Cryst Solids (2019) 524:119648

10. M. I. Sayyed, Y. Al-Hadeethi, Maha M. AlShammari, Moustafa Ahmed, Saleh H. AlHeniti, Y. S. Rammah, "Physical, optical and gamma radiation shielding competence of newly boro-tellurite based glasses: $\mathrm{TeO}_{2}-\mathrm{B}_{2} \mathrm{O}_{3}-\mathrm{ZnO}-\mathrm{Li}_{2} \mathrm{O}_{3}-\mathrm{Bi}_{2} \mathrm{O}_{3}$ ", Journal of ceramics international 47, (2020) 611-618.

11. M.S. Al-Buriahi, Y.S. Rammah," Electronic polarizability, dielectric, and gamma-ray shielding properties of some tellurite-based glasses", Appl. Phys. A Mater. Sci.Process 125 (2019), 678.

12. M. K. Halimah, A. Azuraida, M. Ishak, L. Hasnimulyati," Influence of bismuth oxide on gamma radiation shielding properties of boro-tellurite glass", Journal of non-crystalline solids 512, (2019) 140-147.

13. G. Sousoy," Effect of $\mathrm{TeO}_{2}$ additions on nuclear radiation shielding behavior of $\mathrm{Li}_{2} \mathrm{O}$ $\mathrm{B}_{2} \mathrm{O}_{3}-\mathrm{P}_{2} \mathrm{O}_{5}-\mathrm{TeO}_{2}$ glass system", Journal of ceramic international 46, (2019) 3844-3854.

14. M.I. Sayyed, K.M. Kaky, D.K. Gaikwad, O. Agar, U.P. Gawai, S.O. Baki, "Physical, structural, optical and gamma radiation shielding properties of borate glasses containing heavy metals $\left(\mathrm{Bi}_{2} \mathrm{O}_{3} / \mathrm{MoO}_{3}\right)$. J. Non Cryst. Solids 507, (2019) 30-37.

15. Silvia Barbi, Consuelo Mugoni, Monia Montorsi, Mario Affatigato, Corrado Gatto, Cristina Siligardi, "Structural and optical properties of cerium oxide doped barium bismuth borate glasses". J. Non Cryst. Solids 499, (2018) 183-188.

16. D.K. Gaikwad, M.I. Sayyed, S.N. Botewad, Shamsan S. Obaid, Z.Y. Khattari, U.P. Gawai, FerasAfaneh, M.D. Shirshat, P.P. Pawar," Physical, structural, optical investigation and shielding features of tungsten bismuth tellurite based glasses"Journal of Non-Crystalline Solids 503-504, (2019) 158-168.

17. Kh.S. Shaaban." Optical properties of $\mathrm{Bi}_{2} \mathrm{O}_{3}$ doped borotellurite glasses and glass Ceramics"Optik, 203, (2019) 163976. 
18. J. Tauc, "Amorphous and Liquid Semiconductors", Springer Science \& Business Media, Berlin, (2012).

19. E.A. Davis, N. Mott, "Electronic Processes in Non-crystalline Materials", Clarendon Press, Oxford, (1971).

20.11- A.A. Ali, Y.S. Rammah, R. El-Mallawany, D. Souri," FTIR and UV spectra of pentaternary borate glasses", Measurement, 105, (2017) 72-77.

21.S.Thakur, V. Thakur, A. Kaur, L. Singh, "Structural, optical and thermal properties of nickel doped bismuth borate glasses". J Non Cryst Solids,512, (2019) 60-71.

22. R. El-Mallawany, F.I. El-Agawany, M.S. Al-Buriahi, C. Muthuwong, A. Novatski, Y. S. Rammah " Optical properties and nuclear radiation shielding capacity of $\mathrm{TeO}_{2}-\mathrm{Li}_{2} \mathrm{O}-\mathrm{ZnO}$ glasses" Optical Materials 106 (2020).

23. James E. Turner."Atoms, radiation and radiation protection", Third, Completely Revised and Enlarged Edition,(2007)

24. M.J.Berger, J.H. Hubbell, 1987/99. XCOM: Photon Cross Sections Database. Web Version 1.2, available at http:// physics.nist.gov/xcom, National Institute of Standards and Technology, Gaithersburg, MD 20899, USA, August 1999. Originally published as NBSIR 87-3597, XCOM: Photon Cross Sections on a Personal Computer (July 1987).

25. M.G. Dong, M.I. Sayyed, G. Lakshminarayana, M. Çelikbilek Ersundu, A.E. Ersundu, Priyanka Nayar, M.A. Mahdi, " Investigation of gamma radiation shielding properties of lithium zinc bismuth borate glasses using XCOM program and MCNP5 code", Journal of Non-Crystalline Solids 468 (2017) 12.

26. X-5 Monte Carlo Team, MCNP--- A general Monte Carlo N- Particle Transport code, Version 5, Volume I: Overview and Theory, Los Alamos Report LA- UR-03-1987 (April 24, 2003).

27. N. El khoshakhany, R. Abbas, R. El mallawany, S. F. Hathot," Optical properties and crystallization of bismuth boro-tellurite glasses", Journal of Non- crystalline Solids, 476, 2017, 15-24

28. N. El khoshakhany, Nora Samir,Youssef El sayed," structural, thermal and optical properties of oxy-fluoro borotellurite glasses", J. MATER RES TECHNOLl 9(3), (2020 ) $2946-2959$

29. M. I. Sayyed, M. H. A. Mhareb, ZinahYaseen Abbas, NoufAlmousa, Farah Laariedh, Kawa M. Kakyand S. O. Baki8." Structural, optical, and shielding investigations of $\mathrm{TeO}_{2}-$ 
$\mathrm{GeO}_{2}-\mathrm{ZnO}-\mathrm{Li}_{2} \mathrm{O}-\mathrm{Bi}_{2} \mathrm{O}_{3}$ glass system for radiation protection applications" Applied Physics A, (2019) 125-417.

30. Fouad El-Diasty, Fathy A. Abdel Wahab, Manal Abdel-Baki, "Optical band gap studies on lithium aluminum silicate glasses doped with Cr3+ ions", J. Appl. Phys. 100 (2006) 093511.

31. Aly Saeed, R.M. El shazly, Y.H. Elbashar, A.M. Abou El-azm, M.M. El-Okr, M.N.H. Comsan, A.M. Osman, A.M. Abdal-monem, A.R. El-Sersy, "Gamma ray attenuation in a developed borate glassy system"Radiation Physics and Chemistry 102, (2014) 167-170

32. M.K. Halimah, A. Azuraida, M. Ishak, L. Hasnimulyati, "influence of bismuth oxide on gamma radiation shielding properties of borotellurite glass", Journal of non -crystalline solids 512, (2019) $140-147$

33. R. El-Mallawany, W. M. Abou-Taleb, MA. Naeem, ME. Krar , S. Talaat," Synthesis, physical, optical properties and gamma-ray shielding parameters of some tellurite glasses" Optik 242, (2021) 16717.

34. Y. Al-Hadeethi, M.I. Sayyed, " Radiation attenuation properties of $\mathrm{Bi}_{2} \mathrm{O}_{3}-\mathrm{Na}_{2} \mathrm{O}-\mathrm{V}_{2} \mathrm{O}_{5}-$ $\mathrm{TiO}_{2}-\mathrm{TeO}_{2}$ glass system using Phy-X / PSD software" Ceramics international 46, (2020) 4795-4800.

35. Ozge Kilicoglu, H.O. Tekin, "Bioactive glasses and direct effect of increased $\mathrm{K}_{2} \mathrm{O}$ additive for nuclear shielding performance: A comparative investigation" Ceramics international 46, (2020) 1323-1333. 
Table 1: Sample code, composition, density, molar volume, oxygen packing density and the photograph of the $\left[(60-\mathrm{X}) \mathrm{TeO}_{2}-(20+\mathrm{X}) \mathrm{B}_{2} \mathrm{O}_{3}-10 \mathrm{Li}_{2} \mathrm{O}-10 \mathrm{Bi}_{2} \mathrm{O}_{3}\right]$ glasses where $\mathrm{X}=5,10,15$ and $20 \mathrm{~mol} \%$.

\begin{tabular}{|c|c|c|c|c|c|c|c|c|}
\hline \multirow{2}{*}{$\begin{array}{c}\text { Sample } \\
\text { code }\end{array}$} & \multicolumn{4}{|c|}{ Composition (mol\%) } & \multirow{2}{*}{$\begin{array}{c}\boldsymbol{\rho} \\
\left(\mathrm{g} / \mathrm{cm}^{3}\right)\end{array}$} & \multirow{2}{*}{$\begin{array}{c}\mathbf{V}_{\mathbf{m}} \\
\left(\mathbf{c m}^{3} / \mathbf{m o l}\right)\end{array}$} & \multirow{2}{*}{$\begin{array}{r}\mathrm{OPD} \pm 0.1 \\
(\mathrm{~mol} / \mathrm{liter})\end{array}$} & \multirow{2}{*}{$\begin{array}{l}\text { Photograph of } \\
\text { synthesized } \\
\text { glass samples }\end{array}$} \\
\hline & $\mathrm{TeO}_{2}$ & $\mathbf{B}_{2} \mathrm{O}_{3}$ & $\mathrm{Bi}_{2} \mathrm{O}_{3}$ & $\mathbf{L i}_{2} \mathbf{O}$ & & & & \\
\hline B25 & 55 & 25 & 10 & 10 & 4.8248 & 32.0776 & 70.1423 & \\
\hline B30 & 50 & 30 & 10 & 10 & 4.6643 & 32.2169 & 71.3910 & \\
\hline B35 & 45 & 35 & 10 & 10 & 4.5038 & 32.3661 & 72.6068 & \\
\hline B40 & 40 & 40 & 10 & 10 & 4.3433 & 32.5263 & 73.7864 & \\
\hline
\end{tabular}


Table 2: Various physical and optical parameters of the prepared glasses.

\begin{tabular}{|c|c|c|c|c|c|c|c|c|}
\hline \multirow[t]{3}{*}{$\begin{array}{c}\text { Sample } \\
\text { Code }\end{array}$} & \multicolumn{4}{|c|}{ Optical energy band gab, $E_{\text {opt }}(e V)$} & \multicolumn{4}{|c|}{ Linear refractive index, $n$} \\
\hline & \multicolumn{2}{|c|}{$\left(\boldsymbol{E}_{\text {opt }}\right)_{\text {Tauc's }}$} & \multicolumn{2}{|c|}{$\left(\boldsymbol{E}_{\text {opt }}\right)_{A S F}$} & \multicolumn{2}{|c|}{ Tauc's method } & \multicolumn{2}{|c|}{ ASF mothod } \\
\hline & Direct & Indirect & Direct & Indirect & Direct & Indirect & Direct & Indirect \\
\hline B25 & 2.8975 & 2.6842 & 2.8875 & 2.7234 & 2.4252 & 2.4877 & 2.4280 & 2.4758 \\
\hline B30 & 2.8050 & 2.5443 & 2.8151 & 2.5763 & 2.4516 & 2.5319 & 2.4487 & 2.5216 \\
\hline $\mathbf{B 3 5}$ & 2.7897 & 2.5094 & 2.7787 & 2.5503 & 2.4561 & 2.5435 & 2.4594 & 2.5300 \\
\hline B40 & 2.7312 & 2.4571 & 2.7189 & 2.4747 & 2.4735 & 2.5610 & 2.4802 & 2.5551 \\
\hline
\end{tabular}


Table 3: Optical energy band gaps and refractive indices of synthesized glasses obtained by Tauc's and ASF methods.

\begin{tabular}{|c|c|c|c|c|}
\hline Parameter & B25 & B30 & B35 & B40 \\
\hline Number of oxygen atom & 2.25 & 2.3 & 2.35 & 2.4 \\
\hline Molecular weight $M_{w t}(\mathrm{~mol})$ & 154.77 & 150.27 & 145.77 & 141.27 \\
\hline Ion concentration $\left(N_{i}\right) * 10^{20}\left(\right.$ ions $\left./ \mathrm{cm}^{3}\right)$ & 26.287 & 37.390 & $\mathbf{5 5 . 8 2 7}$ & 74.069 \\
\hline Polaron radius $r_{p}\left(A^{\circ}\right)$ & 2.919 & 2.596 & 2.271 & 2.067 \\
\hline Inter-nuclear distance $r_{i}\left(A^{\circ}\right)$ & 7.245 & 6.443 & 5.637 & 5.130 \\
\hline Molar Refractivity $R_{m}\left(\mathrm{~cm}^{3} / \mathrm{mol}\right)$ & 26.624 & 26.857 & 27.002 & 27.209 \\
\hline Molar Polarizability $\left(\alpha_{m} * 10^{-24} \mathrm{~cm}^{3}\right.$ & 10.559 & 10.652 & 10.709 & 10.792 \\
\hline Metallization ( M ) & 0.170 & 0.166 & 0.165 & 0.163 \\
\hline Reflection loss $\left(R_{L}\right)$ & 0.173 & 0.176 & 0.177 & 0.179 \\
\hline Electro-negativity $(\chi)$ & 0.778 & 0.754 & 0.749 & 0.734 \\
\hline Electro-Polarizability $\left(\alpha^{\circ}\right)$ & 2.799 & 2.821 & 2.825 & 2.839 \\
\hline Optical basicity $(\wedge)$ & 1.311 & 1.323 & 1.325 & 1.333 \\
\hline Urbach energy $(\Delta E)(e V)$ & 0.263 & 0.275 & 0.303 & 0.327 \\
\hline Static dielectric constant, $\varepsilon^{\text {static }}$ & 5.882 & 6.011 & 6.033 & 6.118 \\
\hline Optical dielectric constant, $\varepsilon^{\text {optical }}$ & 4.882 & 5.011 & 5.032 & 5.118 \\
\hline Optical transmission, $T$ & 0.705 & 0.699 & 0.698 & 0.695 \\
\hline
\end{tabular}


Table 4: Shows the mass attenuation coefficient $\left(\mu_{\mathrm{m}}\right)$ values obtained experimentally (EXP) and theoretically by MCNP5 simulation code and XCOM program for samples (B 25, B 30, B 35 and B 40) at different photon energy.

\begin{tabular}{|c|c|c|c|c|c|c|}
\hline $\begin{array}{l}\text { Photon } \\
\text { energy }\end{array}$ & \multicolumn{3}{|c|}{ B25 } & \multicolumn{3}{|c|}{ B30 } \\
\hline $\mathrm{E}(\mathrm{MeV})$ & EXP & MCNP5 & XCOM & EXP & MCNP5 & $\mathrm{XCOM}$ \\
\hline 0.121 & $1.192 \pm 0.033$ & 1.083 & 1.422 & $0.955 \pm 0.035$ & 0.937 & 1.423 \\
\hline 0.343 & $0.181 \pm 0.008$ & 0.139 & 0.166 & $0.133 \pm 0.008$ & 0.137 & 0.166 \\
\hline 0.778 & $0.073 \pm 0.016$ & 0.063 & 0.073 & $0.071 \pm 0.018$ & 0.061 & 0.073 \\
\hline 0.964 & $0.063 \pm 0.015$ & 0.054 & 0.063 & $0.062 \pm 0.012$ & 0.054 & 0.063 \\
\hline 1.111 & $0.057 \pm 0.020$ & 0.051 & 0.057 & $0.052 \pm 0.017$ & 0.051 & 0.057 \\
\hline 1.408 & $0.050 \pm 0.009$ & 0.042 & 0.050 & $0.043 \pm 0.009$ & 0.042 & 0.050 \\
\hline $\begin{array}{c}\text { Photon } \\
\text { energy }\end{array}$ & \multicolumn{3}{|c|}{ B35 } & \multicolumn{3}{|c|}{ B40 } \\
\hline $\mathrm{E}(\mathrm{MeV})$ & EXP & MCNP5 & $\mathrm{XCOM}$ & EXP & MCNP5 & $\mathrm{XCOM}$ \\
\hline 0.121 & $1.051 \pm 0.031$ & 1.023 & 1.424 & $1.008 \pm 0.039$ & 1.005 & 1.424 \\
\hline 0.343 & $0.170 \pm 0.008$ & 0.139 & 0.167 & $0.155 \pm 0.008$ & 0.139 & 0.168 \\
\hline 0.778 & $0.073 \pm 0.020$ & 0.062 & 0.073 & $0.073 \pm 0.016$ & 0.063 & 0.073 \\
\hline 0.964 & $0.063 \pm 0.015$ & 0.054 & 0.063 & $0.063 \pm 0.014$ & 0.055 & 0.063 \\
\hline 1.111 & $0.057 \pm 0.016$ & 0.052 & 0.058 & $0.054 \pm 0.017$ & 0.052 & 0.058 \\
\hline 1.408 & $0.050 \pm 0.009$ & 0.042 & 0.050 & $0.050 \pm 0.009$ & 0.042 & 0.050 \\
\hline
\end{tabular}


Table 5: The macroscopic fast neutron removal cross -section of the prepared glass system.

\begin{tabular}{|c|c|c|c|c|}
\hline \multirow[b]{2}{*}{ Element } & \multicolumn{4}{|c|}{ B25 $\rho=4.8248 \mathrm{~g} / \mathrm{cm}^{3}$} \\
\hline & $\sum_{\mathbf{R}}\left(\mathbf{c m}^{-1}\right)$ & $\begin{array}{c}\text { fraction by } \\
\text { weight }\end{array}$ & $\begin{array}{l}\text { partial density } \\
\qquad\left(\mathrm{g} / \mathrm{cm}^{3}\right)\end{array}$ & $\sum_{\mathrm{R}}\left(\mathbf{c m}^{-1}\right)$ \\
\hline Te & 0.029317 & 0.453452 & 2.187815 & 0.029317 \\
\hline $\mathbf{O}$ & 0.045450 & 0.2325971 & 1.122234 & 0.045450 \\
\hline $\mathbf{B}$ & 0.009689 & 0.0349264 & 0.168513 & 0.009689 \\
\hline $\mathbf{B i}$ & 0.013408 & 0.2700558 & 1.302965 & 0.013408 \\
\hline $\mathbf{L i}$ & 0.003635 & 0.0089695 & 0.043276 & 0.003635 \\
\hline \multirow[b]{3}{*}{ Element } & & & & 0.101499 \\
\hline & \multicolumn{4}{|c|}{ B30 $\quad \rho=4.6643 \mathrm{~g} / \mathrm{cm}^{3}$} \\
\hline & $\sum_{\mathbf{R} / \mathbf{\rho}}\left(\mathrm{cm}^{2} / \mathbf{g}\right)$ & $\begin{array}{l}\text { fraction by } \\
\text { weight }\end{array}$ & $\begin{array}{l}\text { partial density } \\
\qquad\left(\mathrm{g} / \mathrm{cm}^{3}\right)\end{array}$ & $\sum_{\mathrm{R}}\left(\mathbf{c m}^{-1}\right)$ \\
\hline Te & 0.0134 & 0.4245708 & 1.980326 & 0.026536 \\
\hline $\mathbf{O}$ & 0.0405 & 0.2448843 & 1.142214 & 0.046260 \\
\hline B & 0.0575 & 0.0431665 & 0.201342 & 0.011577 \\
\hline $\mathbf{B i}$ & 0.0103 & 0.2781409 & 1.297333 & 0.013350 \\
\hline $\mathbf{L i}$ & 0.0840 & 0.0092381 & 0.043089 & 0.003619 \\
\hline \multirow{3}{*}{ Element } & & & & 0.101342 \\
\hline & \multicolumn{4}{|c|}{ B35 $\quad \rho=4.5038 \mathrm{~g} / \mathrm{cm}^{3}$} \\
\hline & $\sum_{\mathrm{R} / \mathbf{p}}\left(\mathrm{cm}^{2} / \mathbf{g}\right)$ & $\begin{array}{l}\text { fraction by } \\
\text { weight }\end{array}$ & $\begin{array}{l}\text { partial density } \\
\left(\mathrm{g} / \mathrm{cm}^{3}\right)\end{array}$ & $\sum_{\mathrm{R}}\left(\mathrm{cm}^{-1}\right)$ \\
\hline Te & 0.0134 & 0.3939068 & 1.774077 & 0.023773 \\
\hline $\mathbf{O}$ & 0.0405 & 0.2579301 & 1.161666 & 0.047047 \\
\hline $\mathbf{B}$ & 0.0575 & 0.0519152 & 0.233816 & 0.013444 \\
\hline $\mathbf{B i}$ & 0.0103 & 0.2867252 & 1.291353 & 0.013288 \\
\hline $\mathbf{L i}$ & 0.0840 & 0.0095232 & 0.042891 & 0.003603 \\
\hline \multirow[b]{3}{*}{ Element } & & & & 0.101155 \\
\hline & \multicolumn{4}{|c|}{ B40 $\quad \rho=4.3433 \mathrm{~g} / \mathrm{cm}^{3}$} \\
\hline & $\sum_{\mathrm{R} / \mathrm{p}}\left(\mathrm{cm}^{2} / \mathrm{g}\right)$ & $\begin{array}{c}\text { fraction by } \\
\text { weight }\end{array}$ & $\begin{array}{l}\text { partial density } \\
\left(\mathrm{g} / \mathrm{cm}^{3}\right)\end{array}$ & $\sum_{\mathrm{R}}\left(\mathrm{cm}^{-1}\right)$ \\
\hline Te & 0.0134 & 0.3612899 & 1.569190 & 0.021027 \\
\hline $\mathbf{O}$ & 0.0405 & 0.2718067 & 1.180538 & 0.047812 \\
\hline $\mathbf{B}$ & 0.0575 & 0.0612211 & 0.265902 & 0.015289 \\
\hline $\mathbf{B i}$ & 0.0103 & 0.2958563 & 1.284993 & 0.013223 \\
\hline \multirow[t]{2}{*}{$\mathbf{L i}$} & 0.0840 & 0.0098264 & 0.042679 & 0.003585 \\
\hline & & & & 0.100936 \\
\hline
\end{tabular}




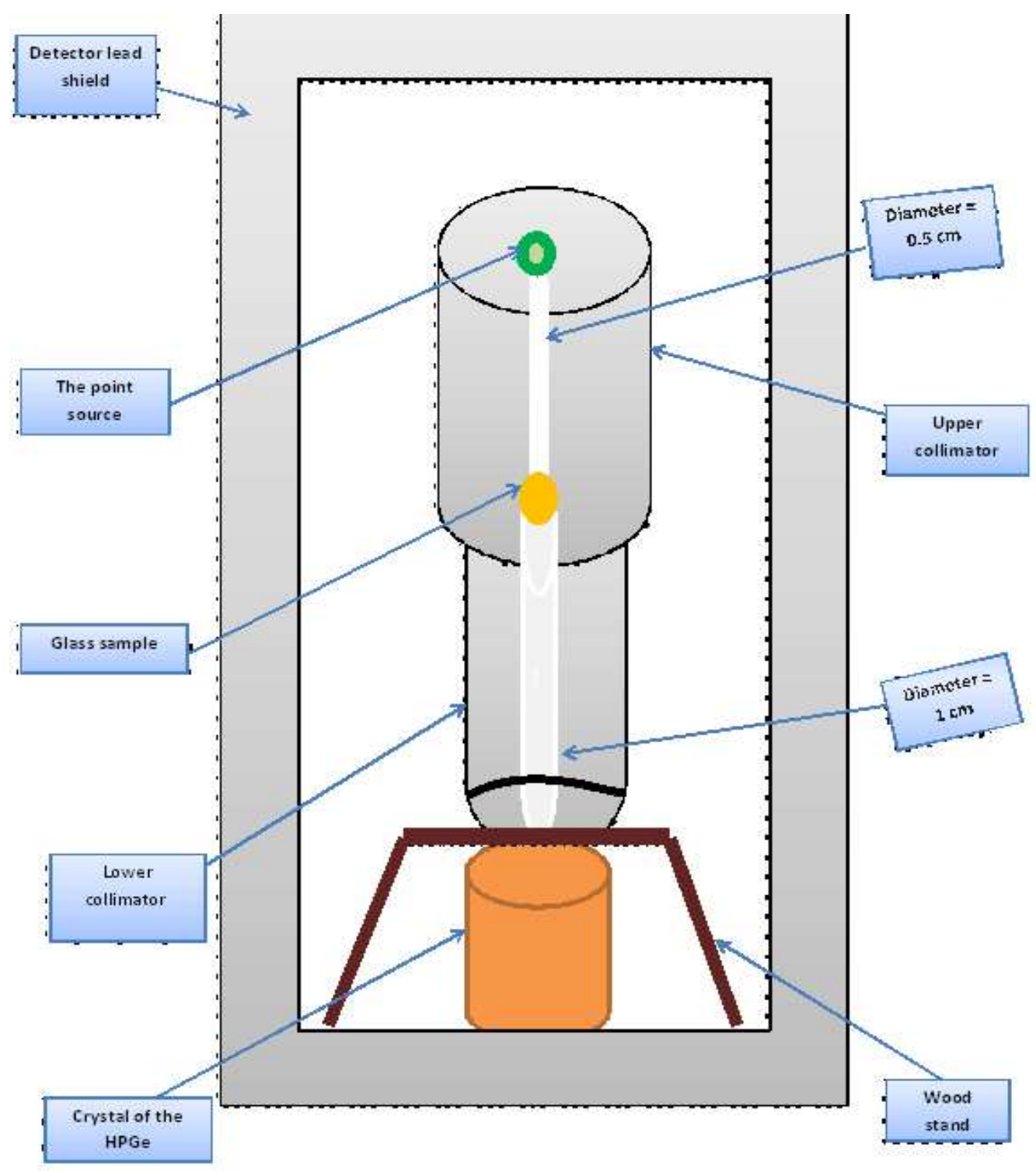

Fig.1a: Schematic experimental setup arrangement. The diagram shows the lead collimators, the sample position and co- axial HPGe detector. 


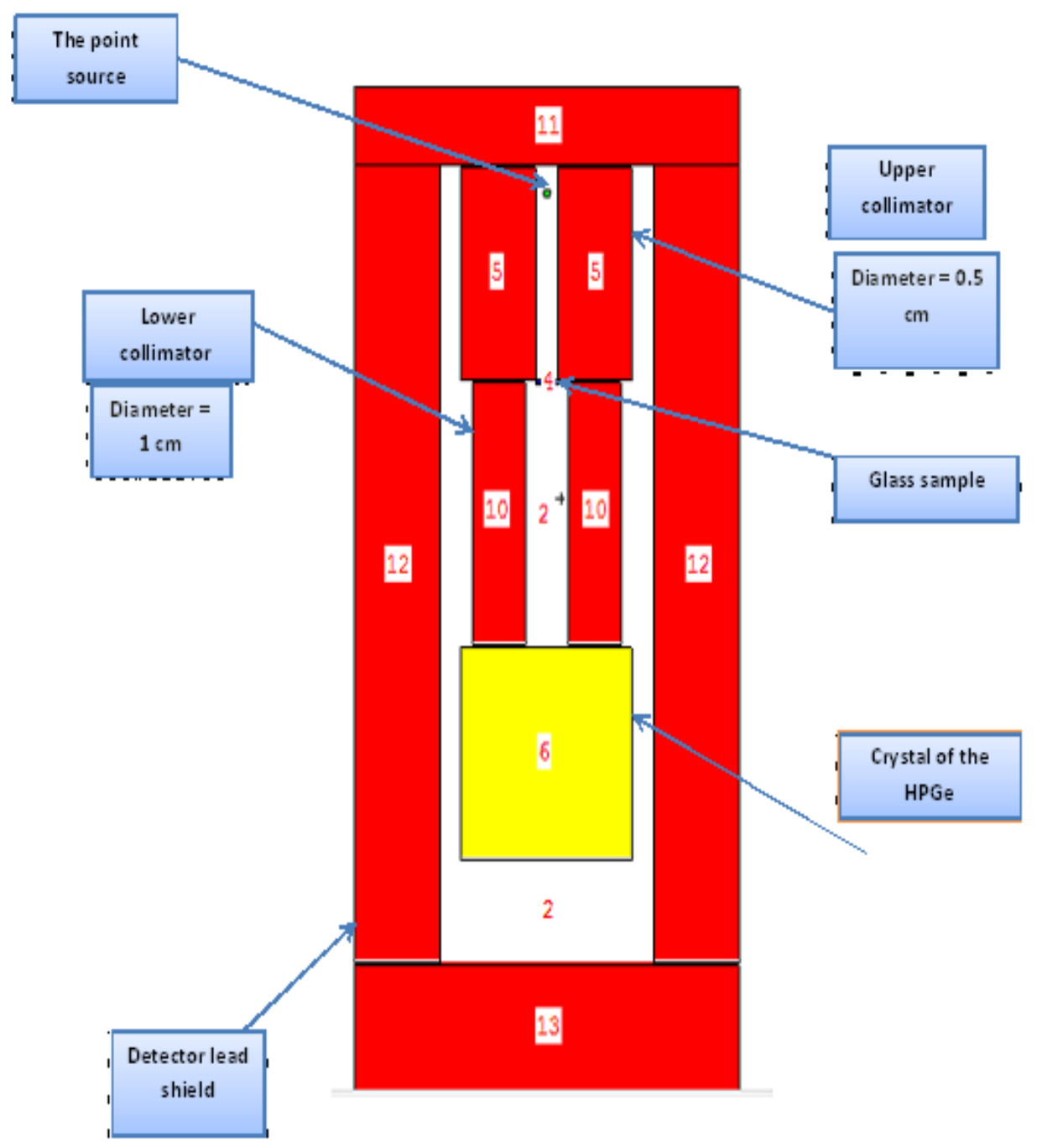

Fig.1b: MCNP5 simulation setup obtained from MCNP5 visual editor for mass attenuation coefficient. 


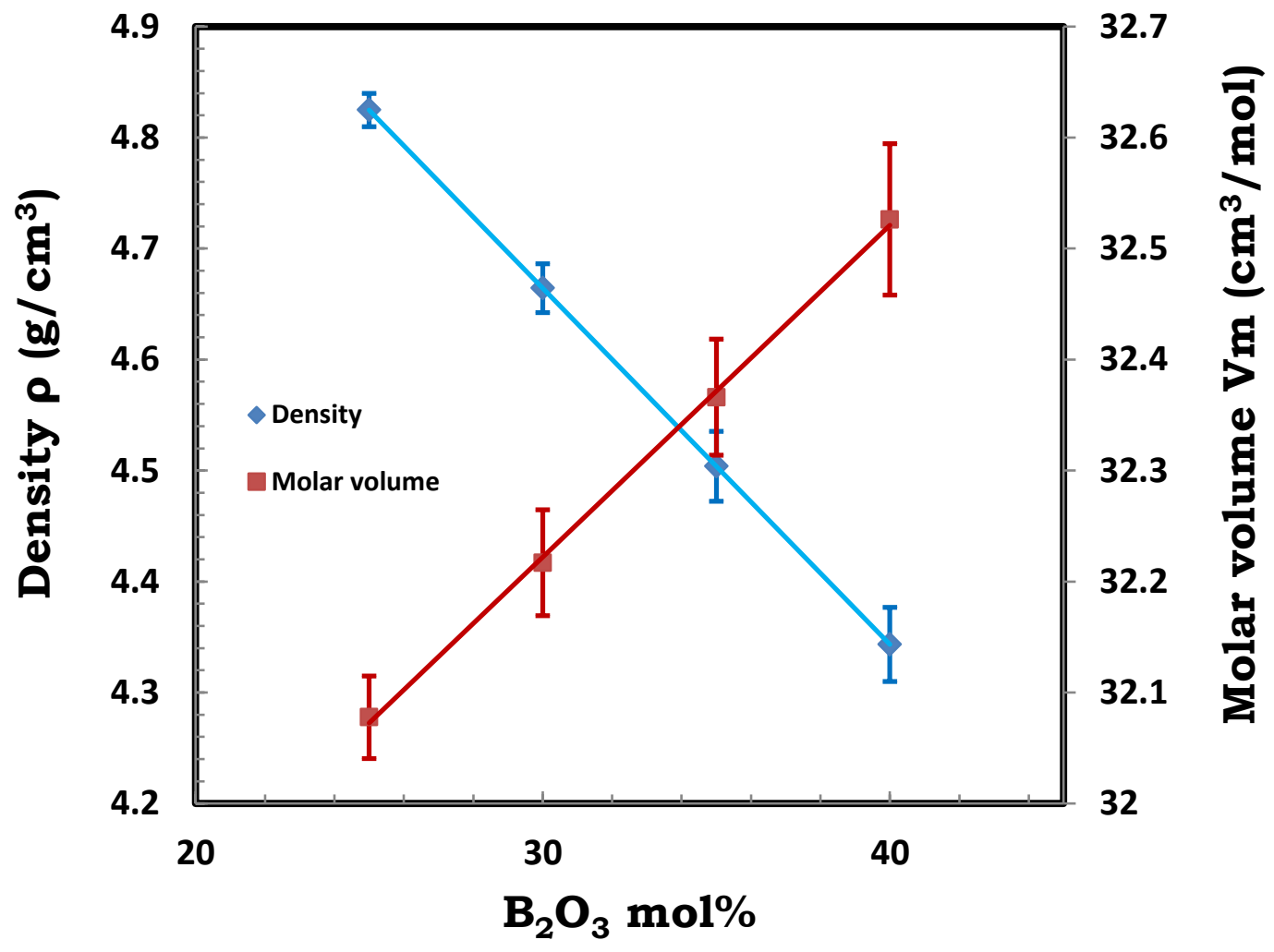

Fig.2: The variation of density and molar volume vs. $\mathrm{B}_{2} \mathrm{O}_{3}$ mol\% for all studied glass samples 


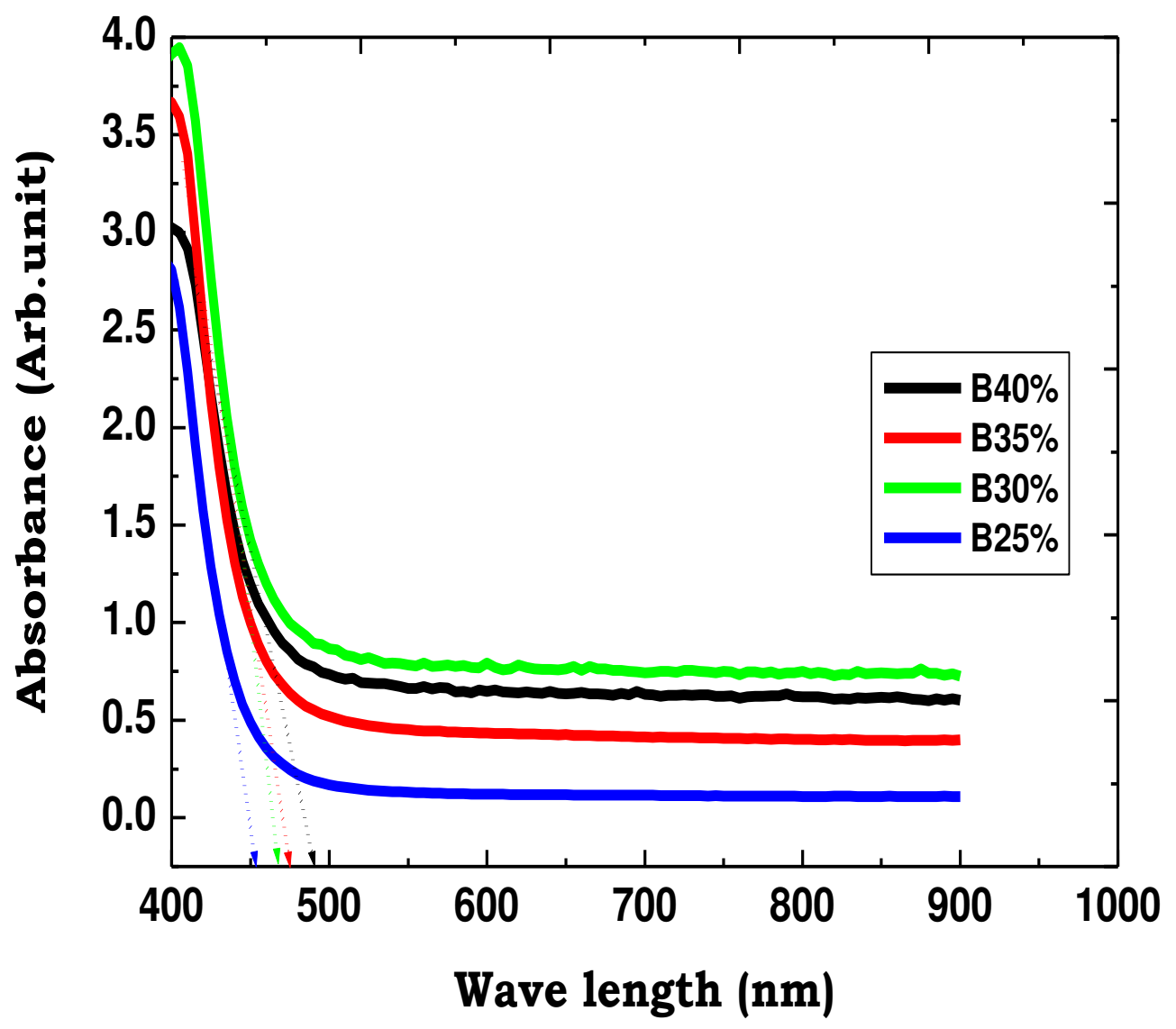

Fig. 3: Optical absorption spectra of the glass samples. 


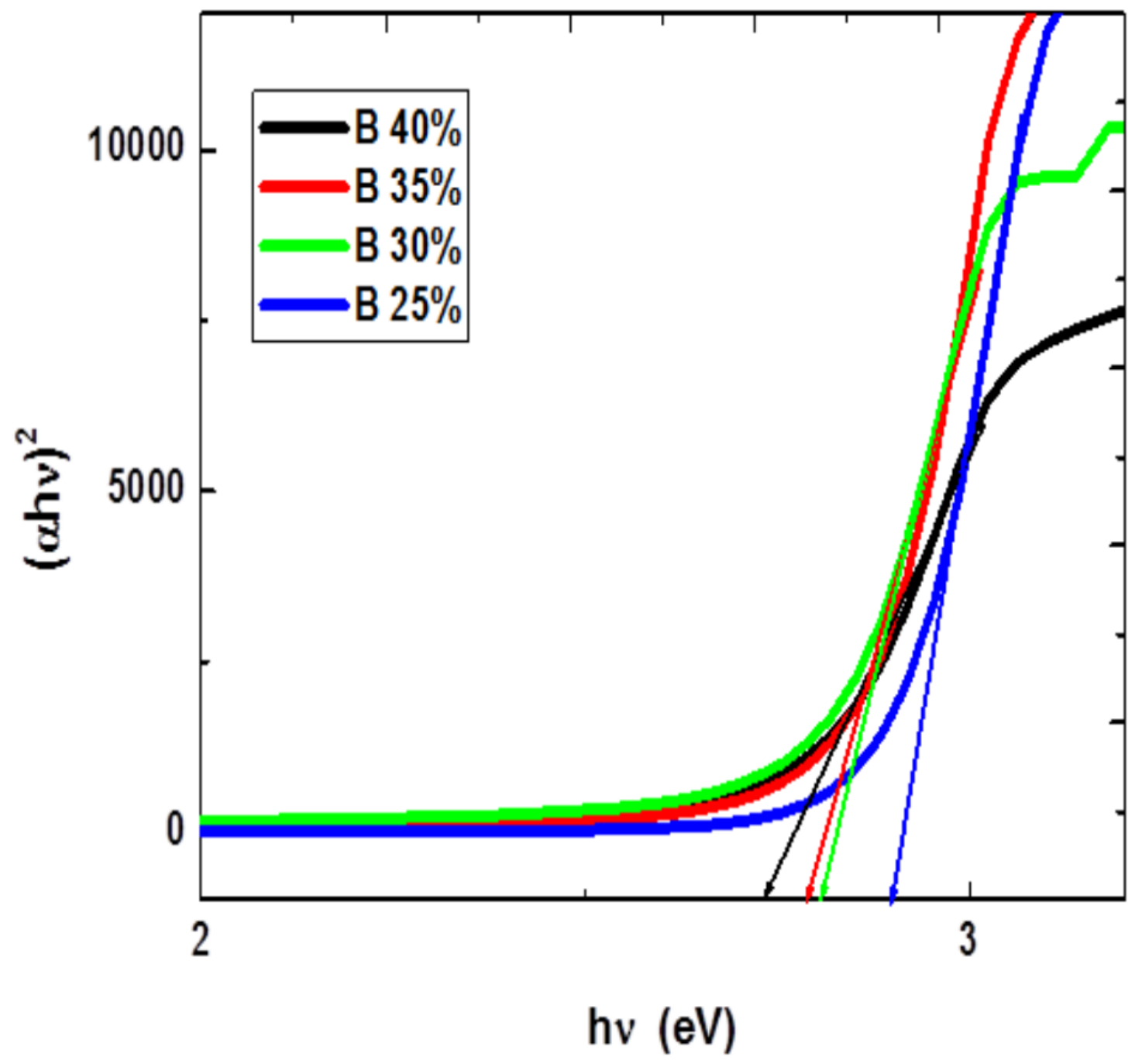

Fig. 4a: Variation of $(\alpha h v)^{2}$ vs. (hv) for glass samples (direct) Tauc's method. 


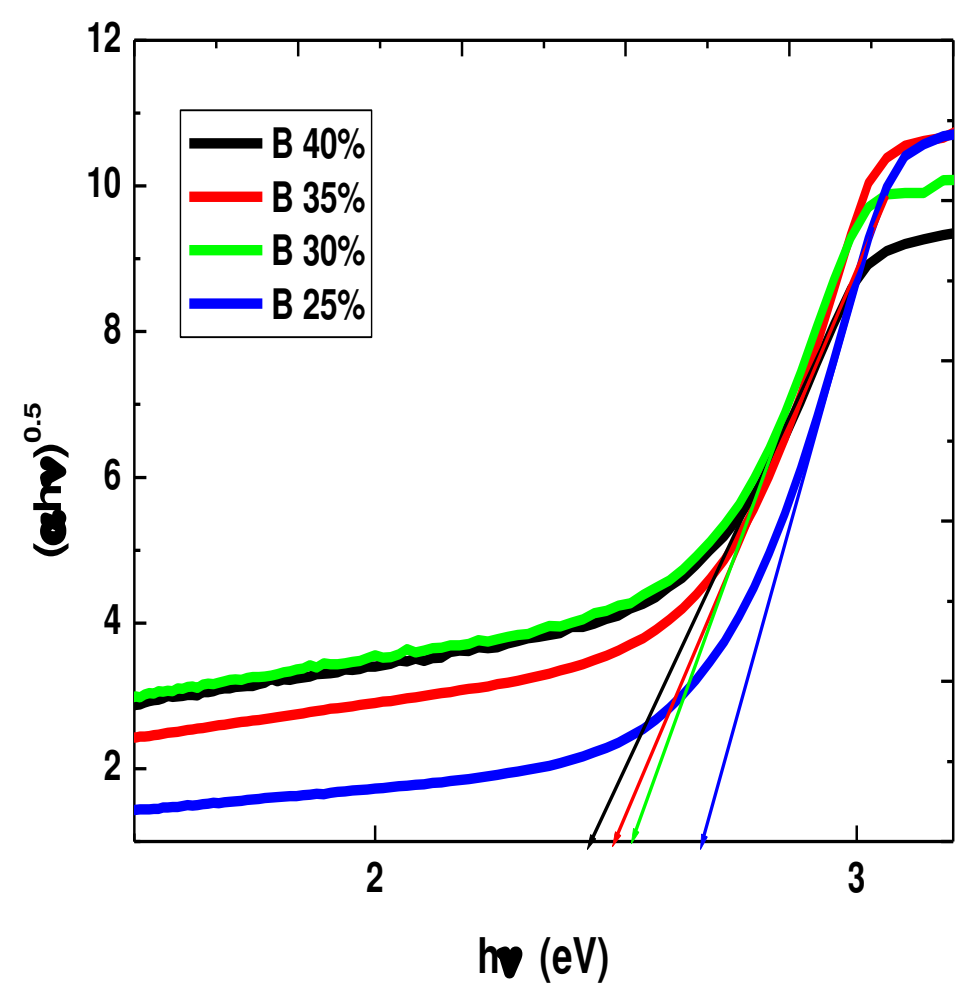

Fig. 4 b: Variation of $(\alpha h v)^{0.5}$ vs. (hv) for glass samples (indirect) Tauc's method. 


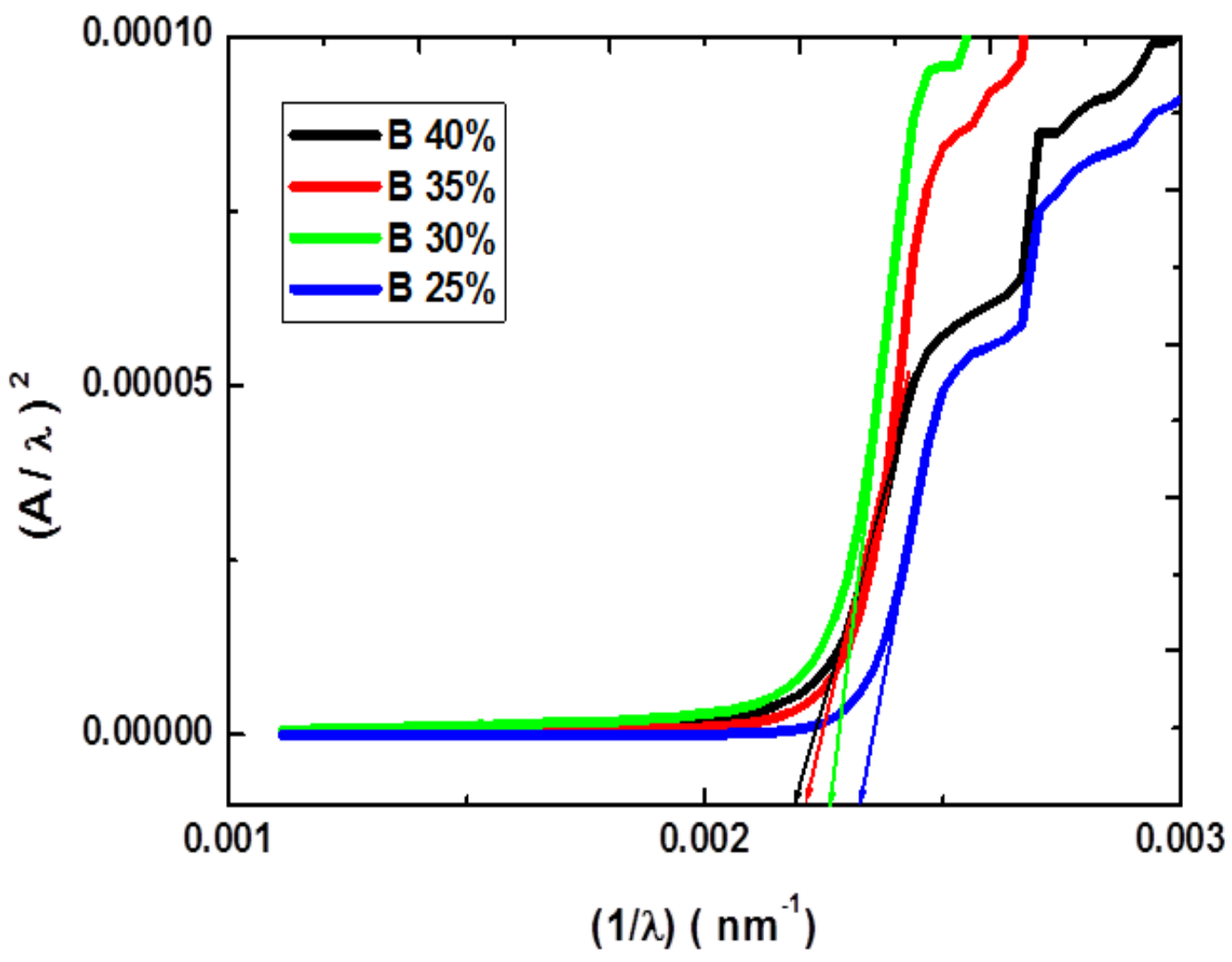

Fig. 5a: Variation of $(\mathrm{A} / \lambda)^{2}$ vs.(1/ $\left.\lambda\right)$ for glass samples (direct) $)_{\text {ASF }}$ method. 


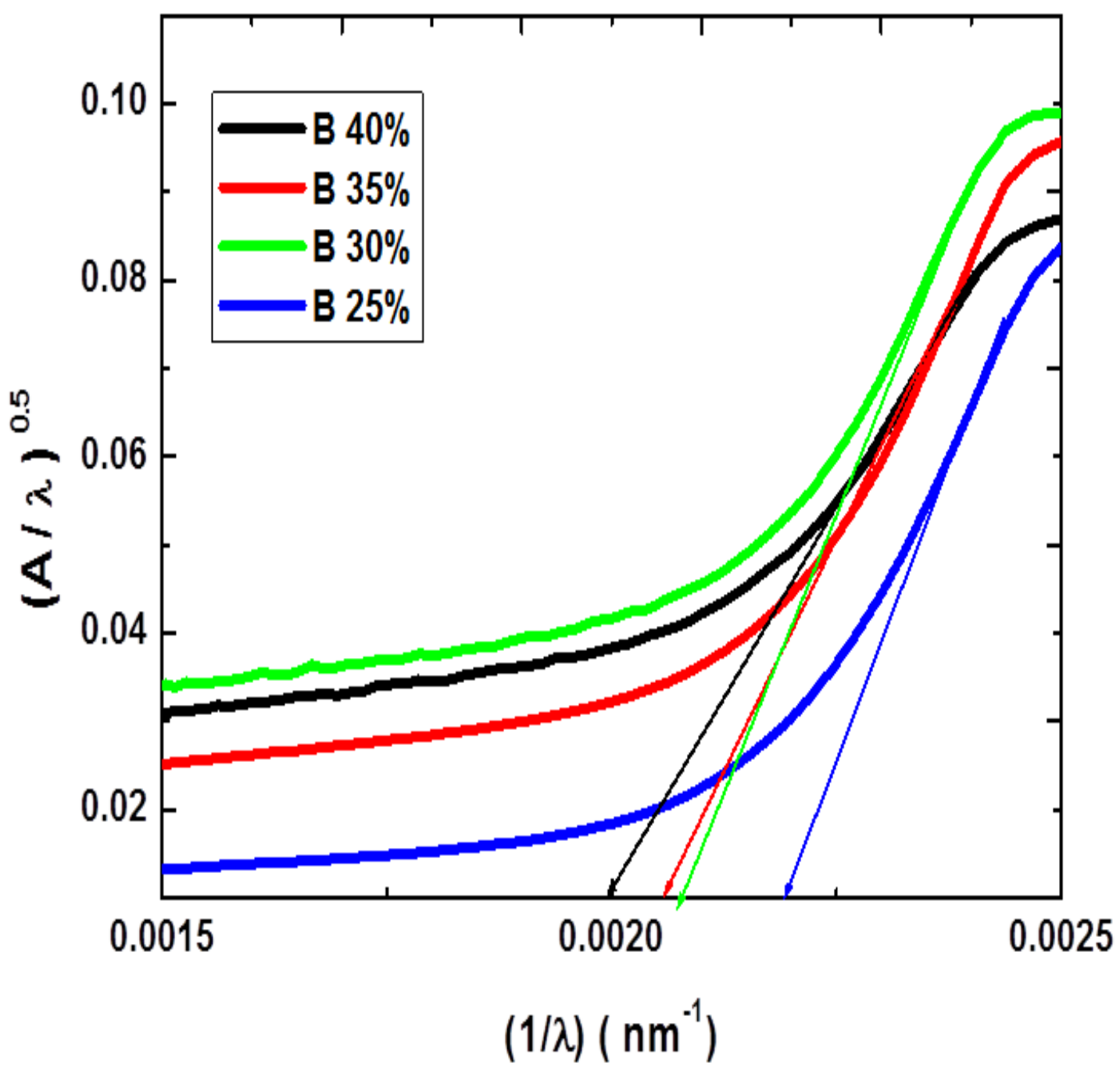

Fig. 5b: Variation of $(\mathrm{A} / \lambda)^{1 / 2}$ vs.(1/ $\lambda$ ) for glass samples (indirect) $)_{\mathrm{ASF}}$ method. 


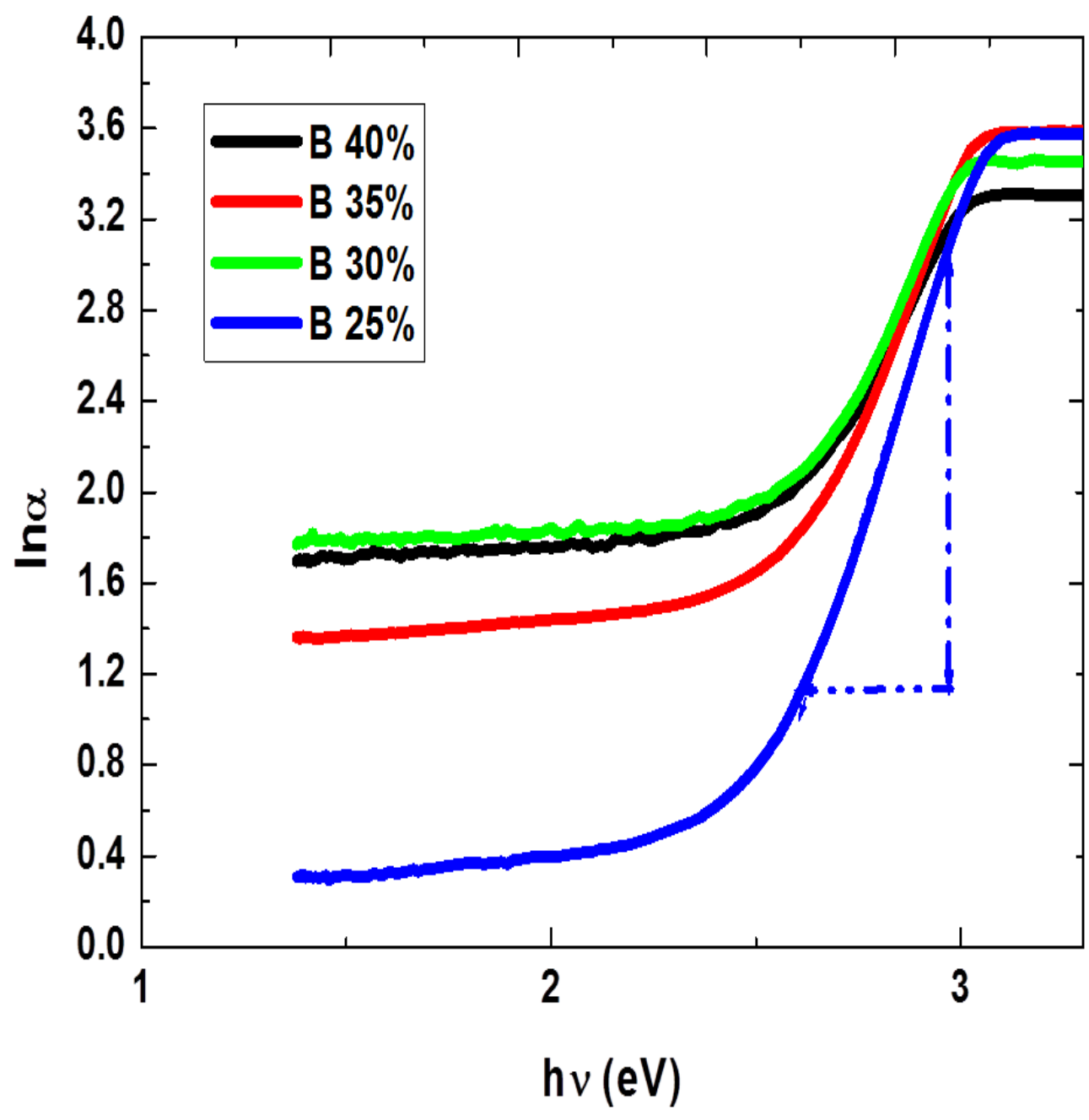

Fig.6: the graph represents the variation of $\ln \alpha$ vs. ho (eV) for all glass samples. 


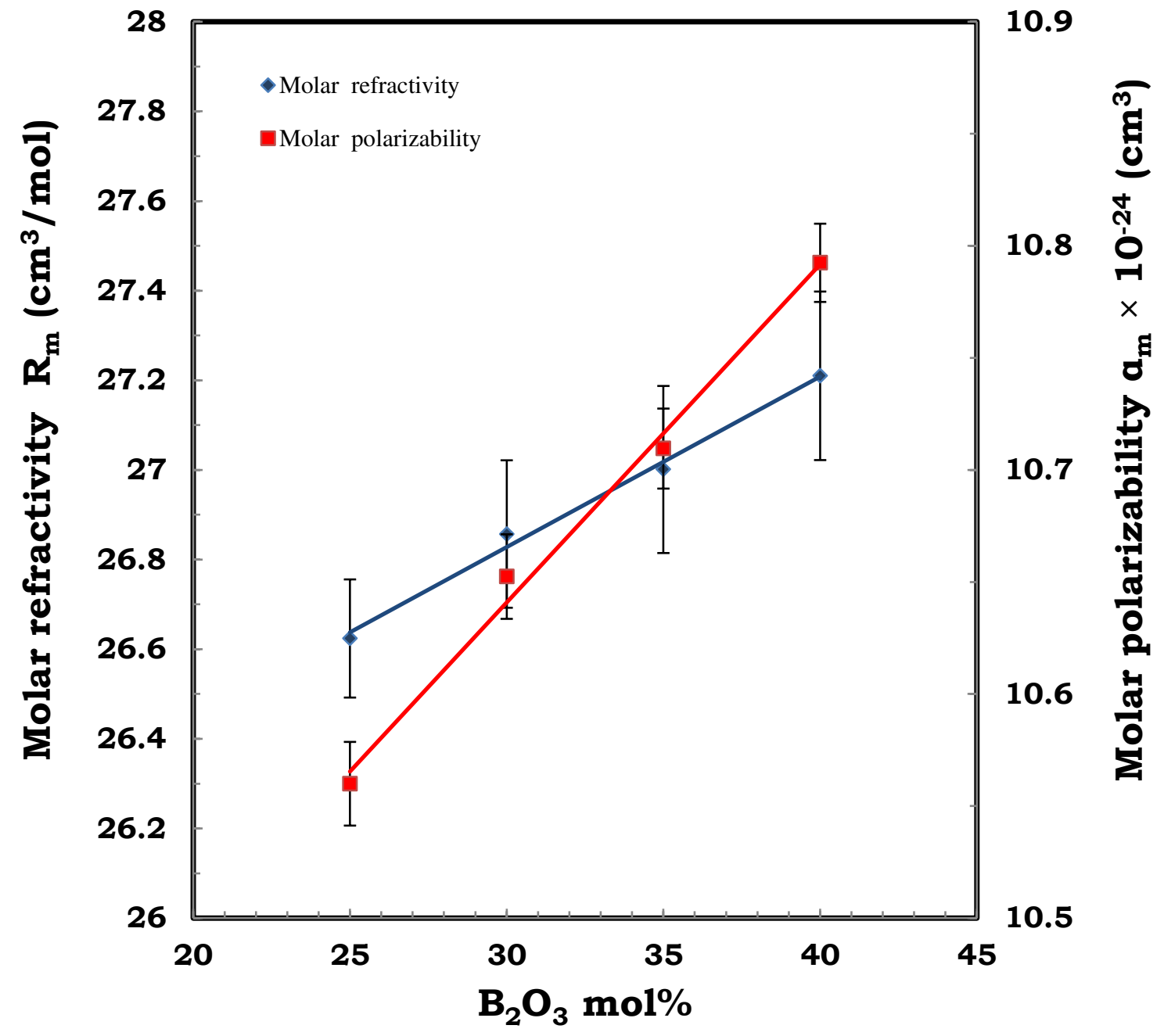

Fig. 7: Variation of $\mathrm{R}_{\mathrm{m}}$ and $\alpha_{\mathrm{m}}$ with $\mathrm{B}_{2} \mathrm{O}_{3} \mathrm{~mol} \%$ for all glasses. 


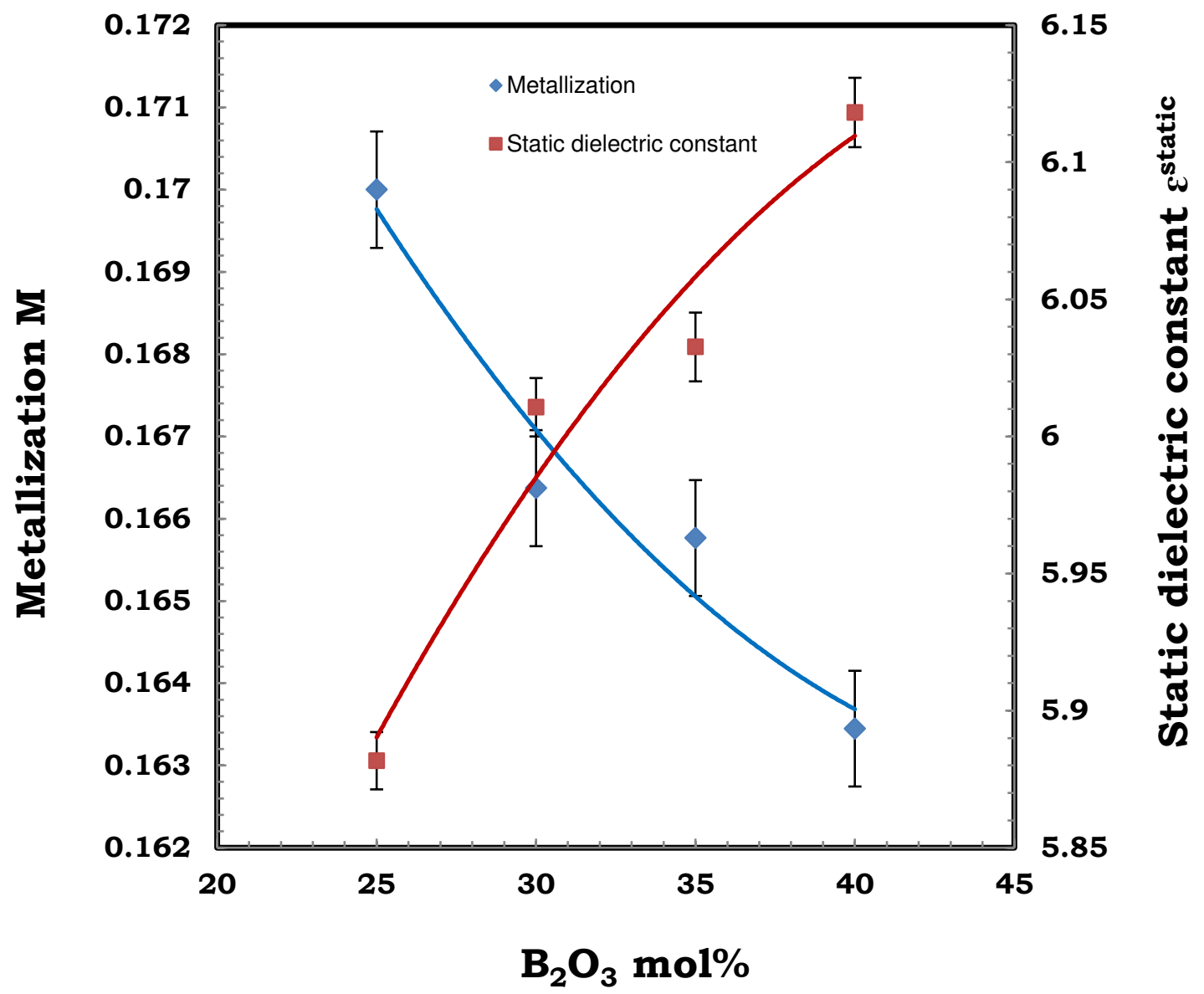

Fig. 8: Variation of $\mathrm{M}$ and $\varepsilon^{\text {static }}$ with $\mathrm{B}_{2} \mathrm{O}_{3}$ mol\% for all glasses. 


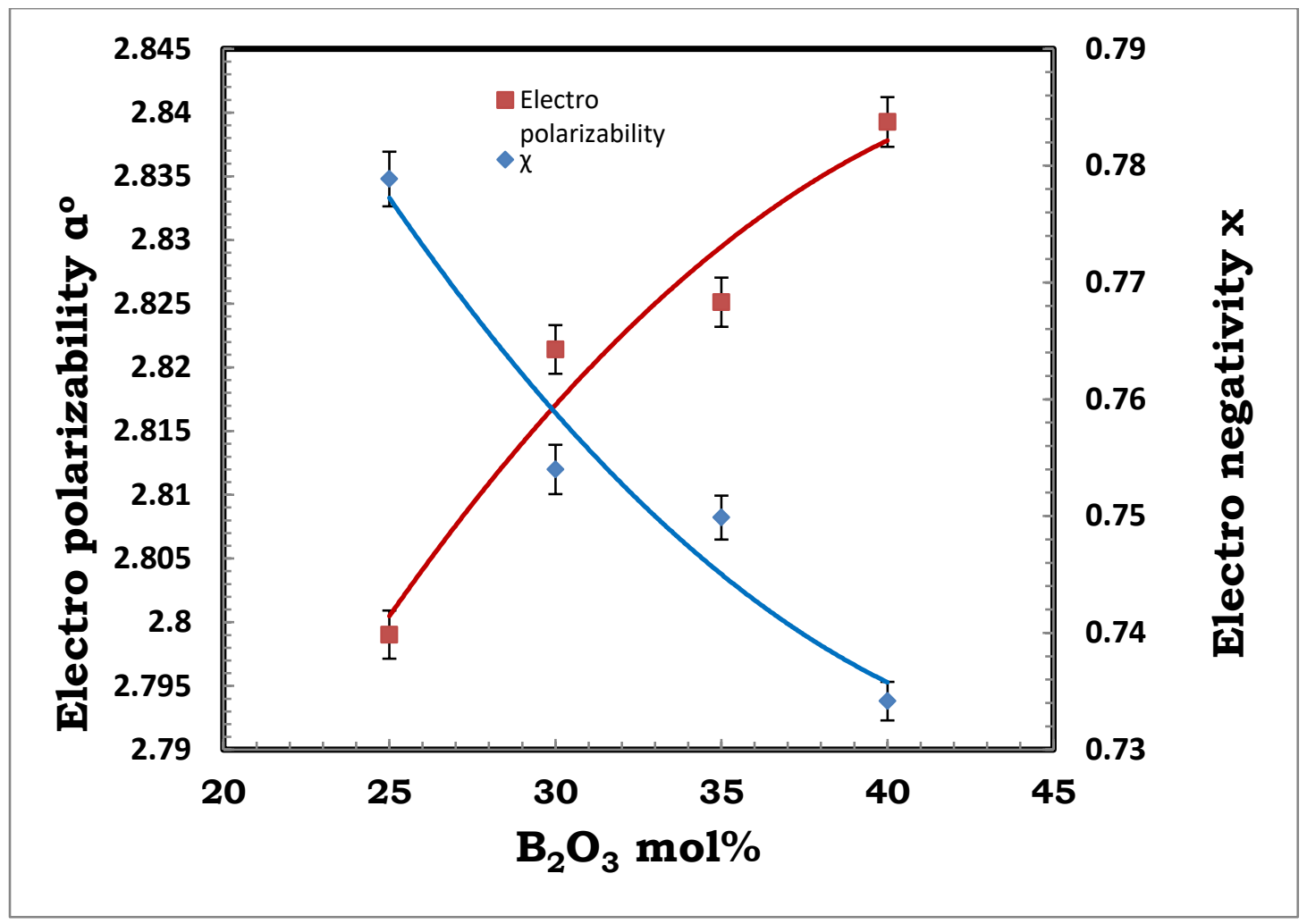

Fig. 9: Variation of $\alpha^{\circ}$ and $\chi$ vs. $\mathrm{B}_{2} \mathrm{O}_{3}$ mol\% for all glasses. 


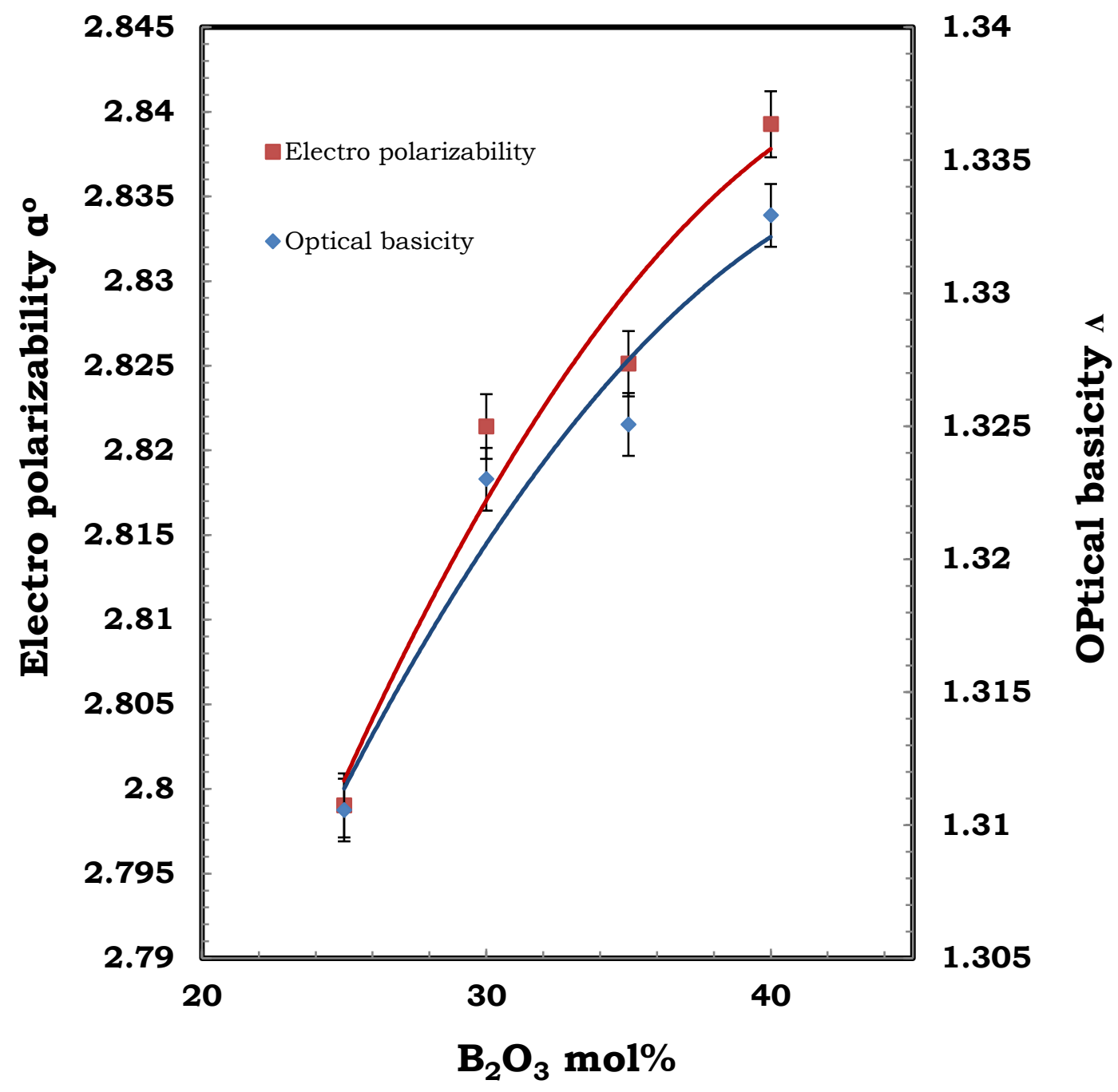

Fig. 10: Variation of $\alpha^{\circ}$ and $\wedge$ with $\mathrm{B}_{2} \mathrm{O}_{3}$ mol\% for all glasses. 

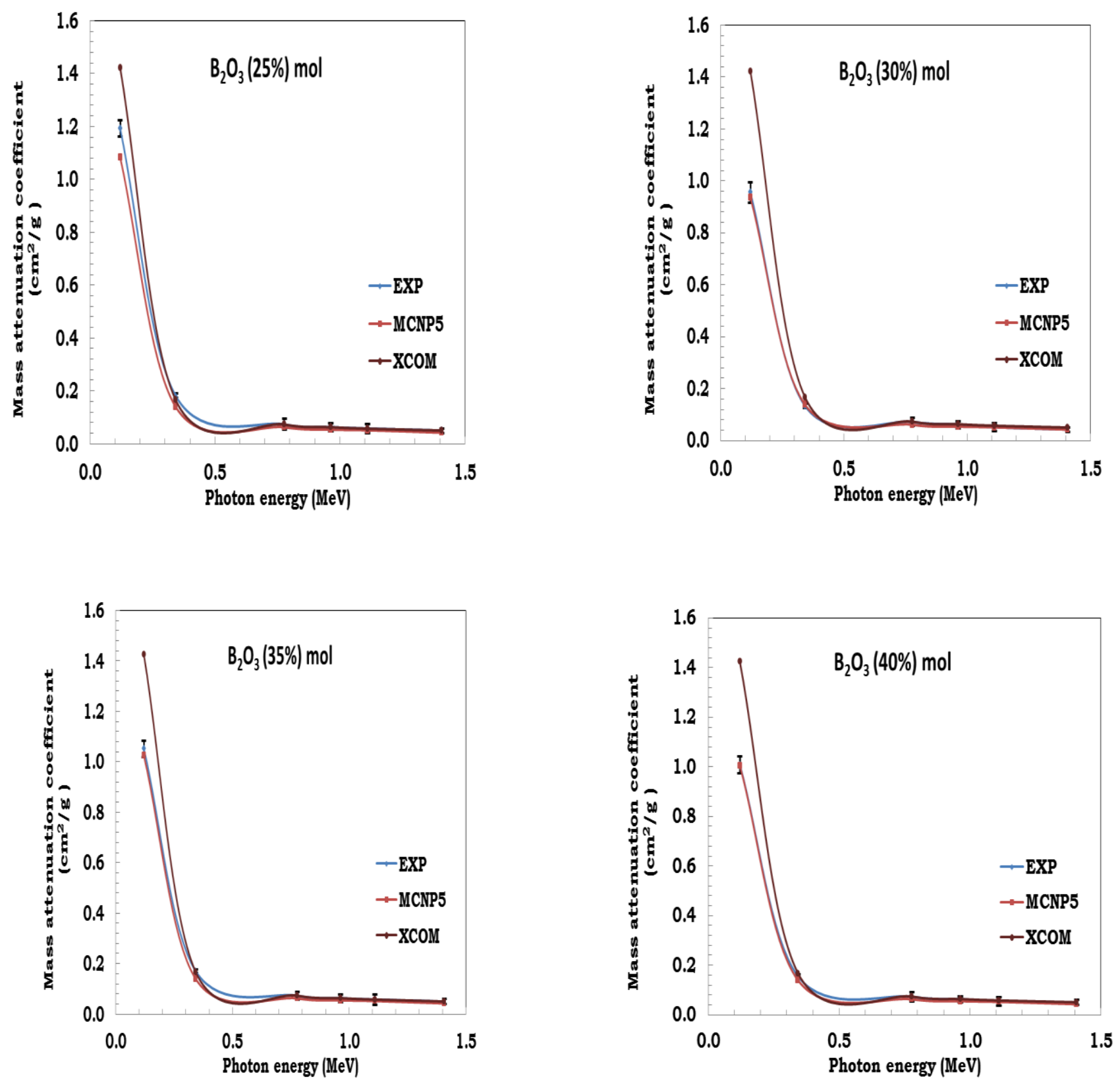

Fig.11: Variation of mass attenuation coefficient $\left(\mathrm{cm}^{2} / \mathrm{g}\right)$ of glass samples based on $\mathrm{B}_{2} \mathrm{O}_{3}$ mol\% content with photon energy calculated by experimental method and theoretically by XCOM and MCNP5 simulation code. 


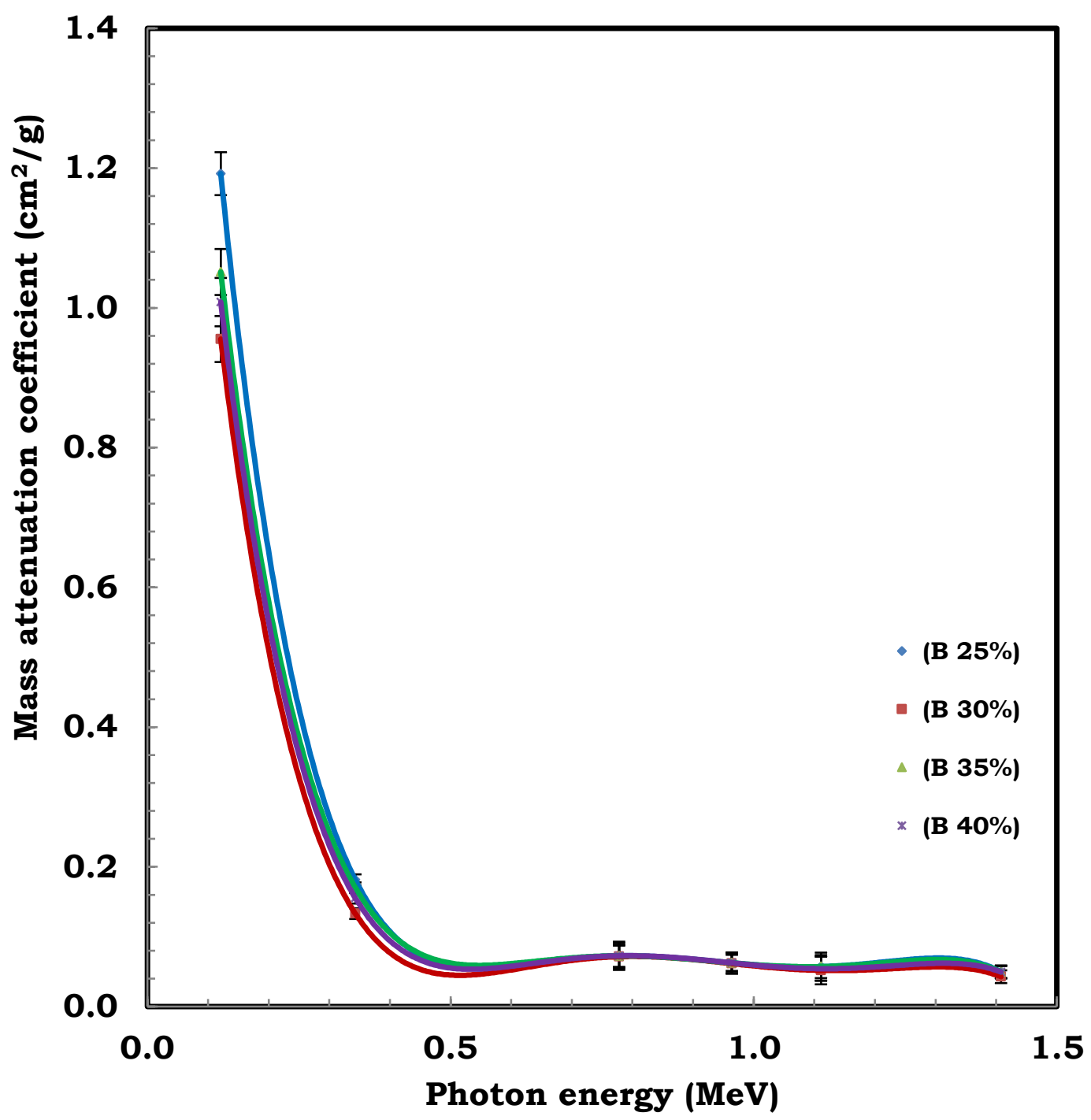

Fig.12: Mass attenuation coefficient $\left(\mu_{\mathrm{m}}\right)$ EXP of the glasses as a function of the photon energy 


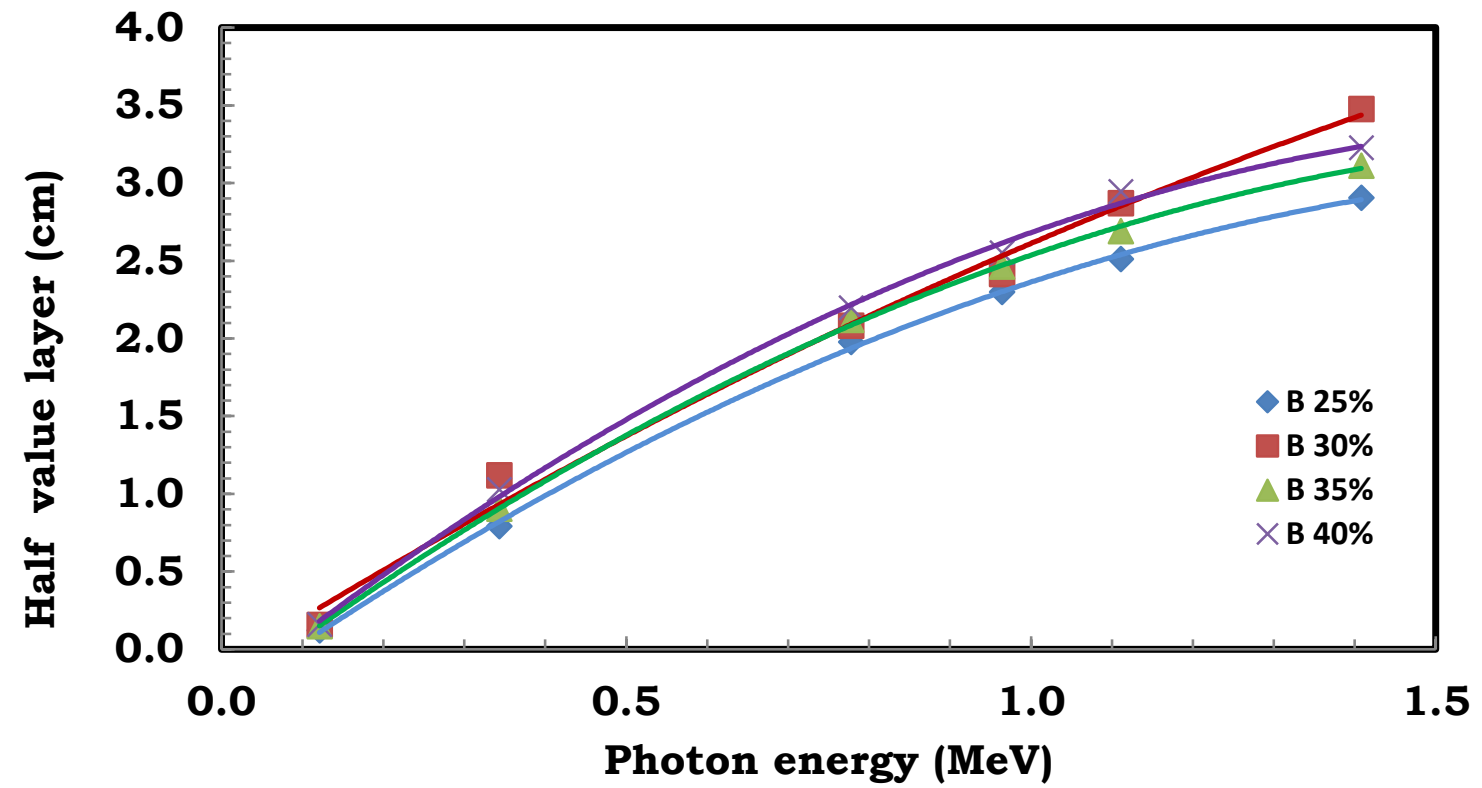

Fig. 13: Half value layer (HVL) of the all glasses as a function of the photon energy. 


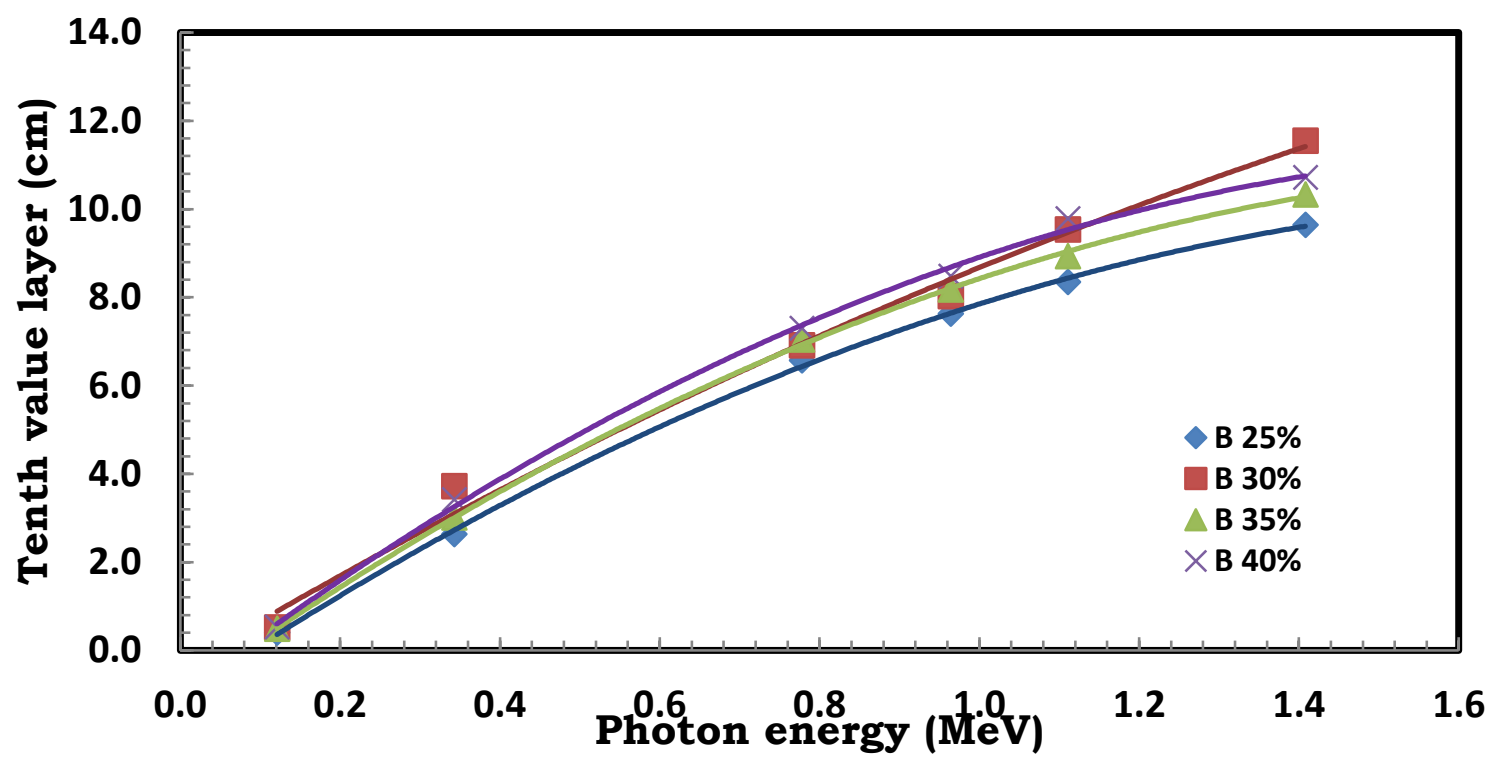

Fig. 14: Tenth value layer (TVL) of the glasses as a function of photon energy.

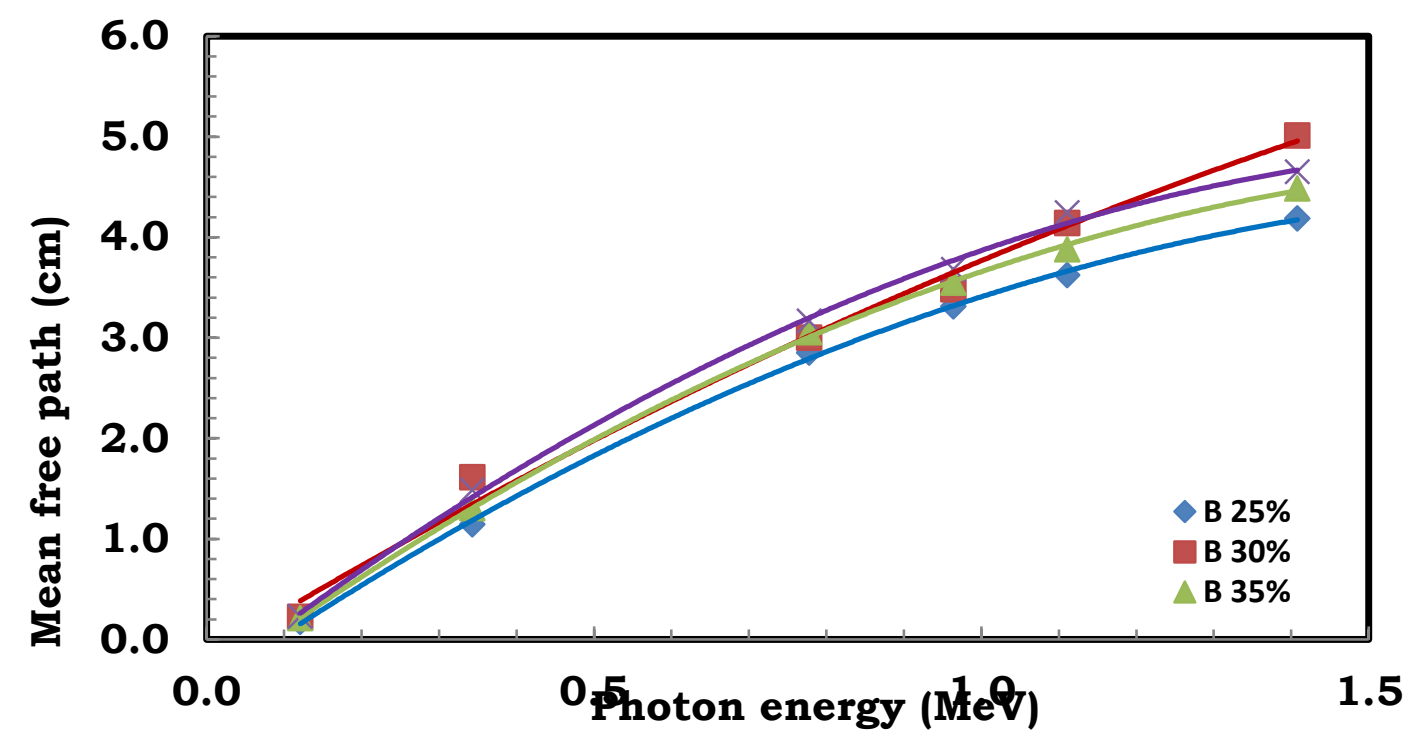

Fig. 15: Mean free path (MFP) of the glasses as a function of photon energy. 


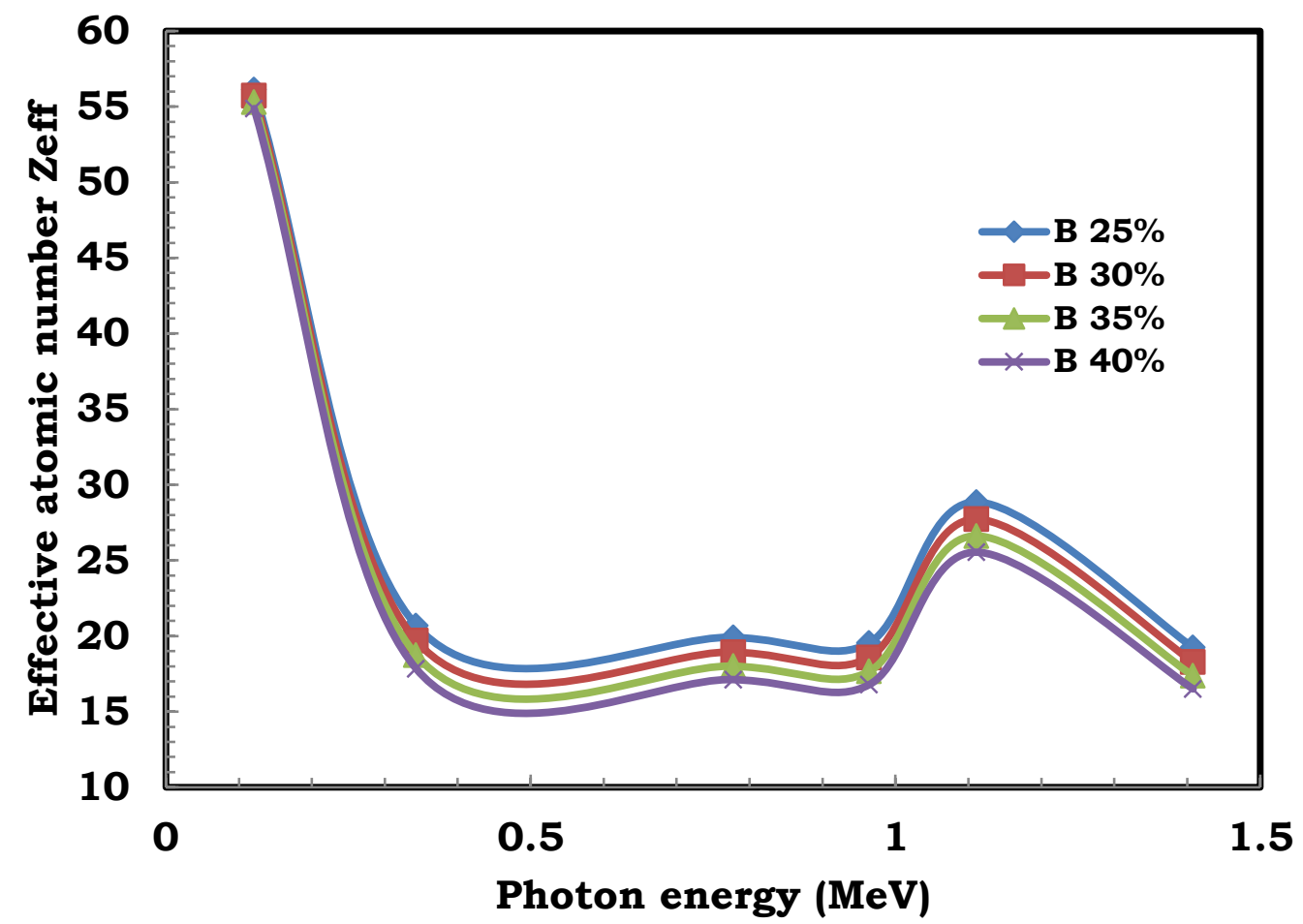

Fig. 16: Effective atomic number $\left(Z_{\text {eff }}\right)$ of the glasses as a function of photon energy. 


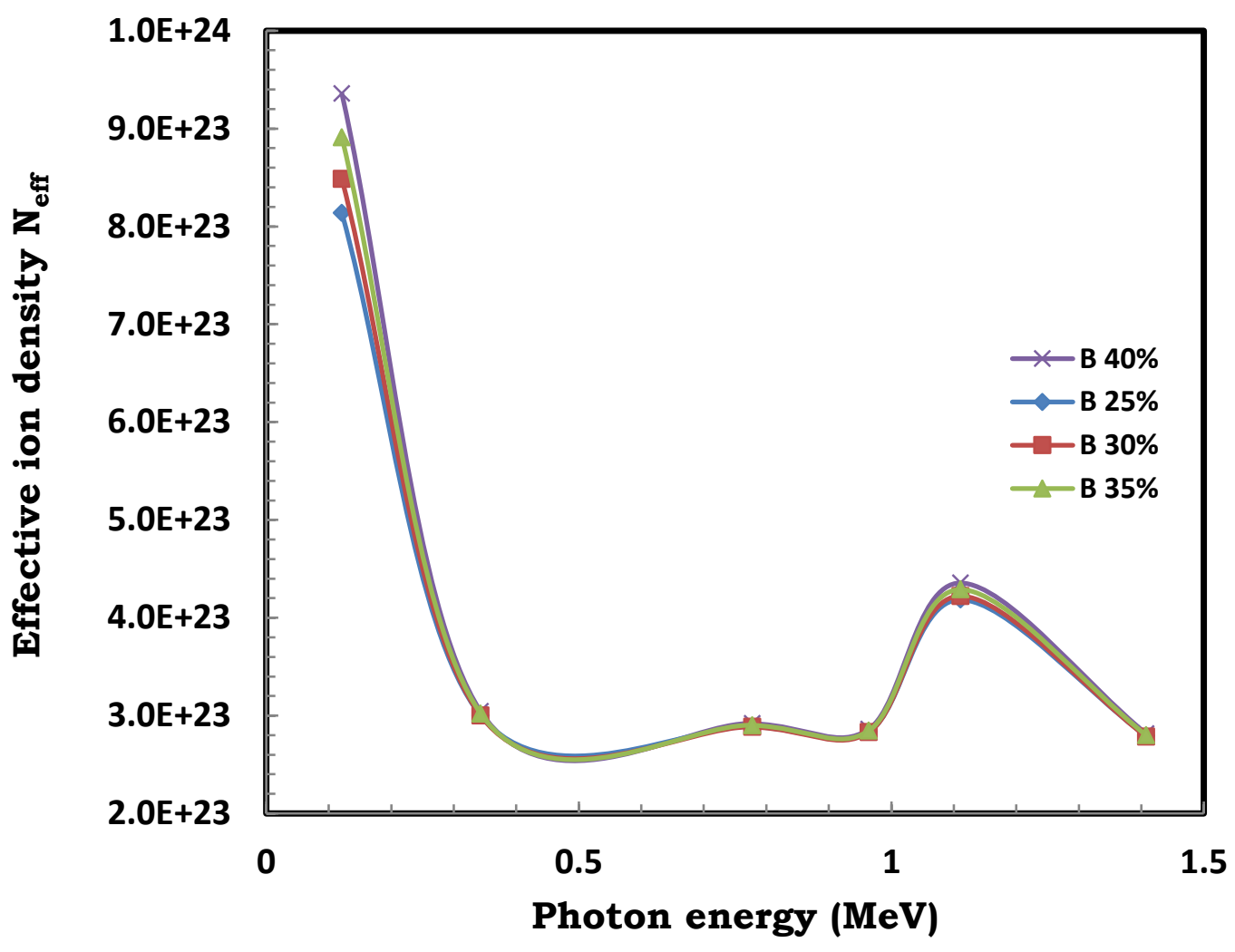

Fig. 17: Variation of effective ion density $\left(\mathrm{N}_{\text {eff }}\right)$ values of all glasses at different photon energies. 


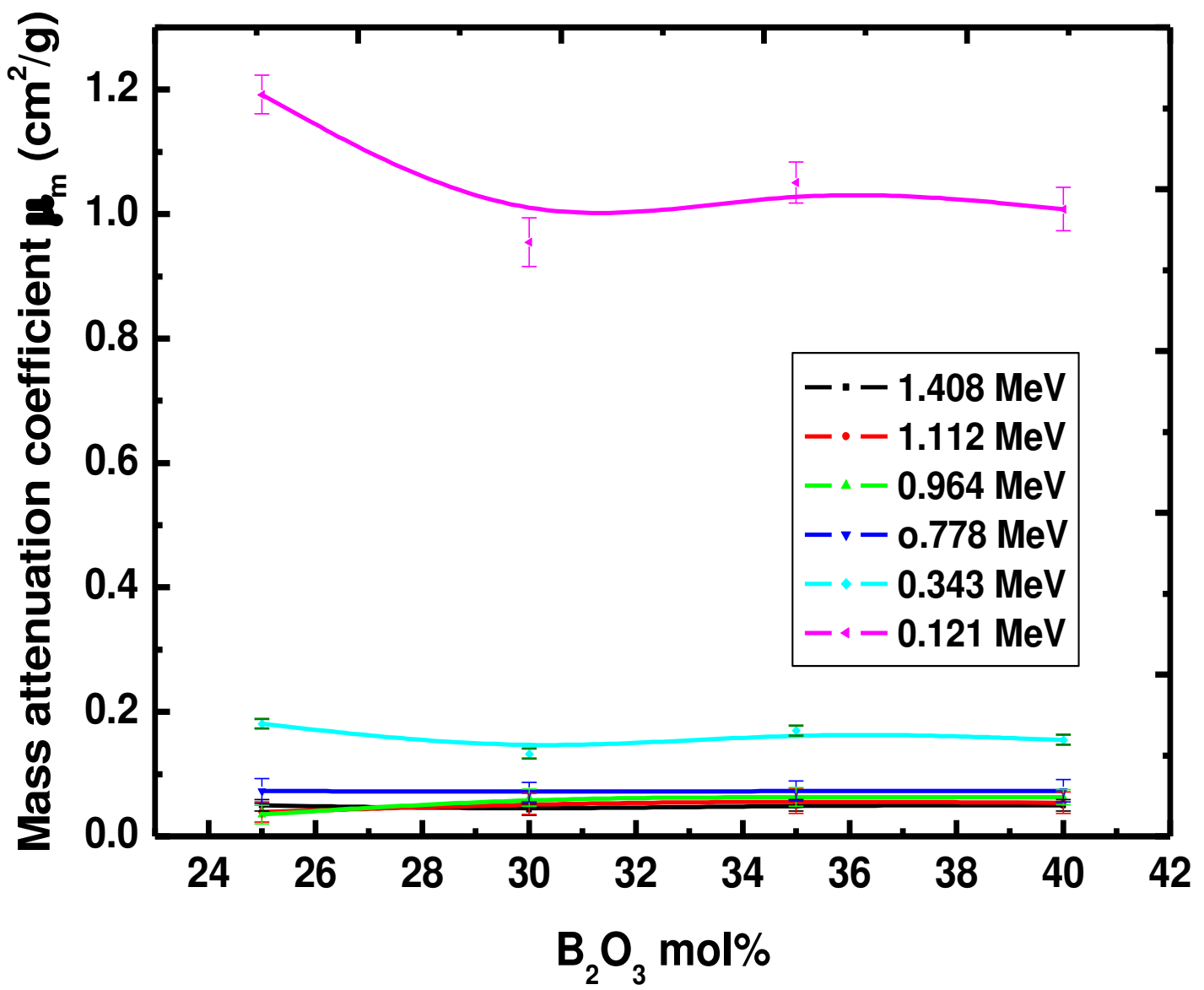

Fig. 18: Dependence of $\mu_{\mathrm{m}}\left(\mathrm{cm}^{2} / \mathrm{g}\right)$ values on the $\mathrm{B}_{2} \mathrm{O}_{3} \mathrm{~mol} \%$ content. 


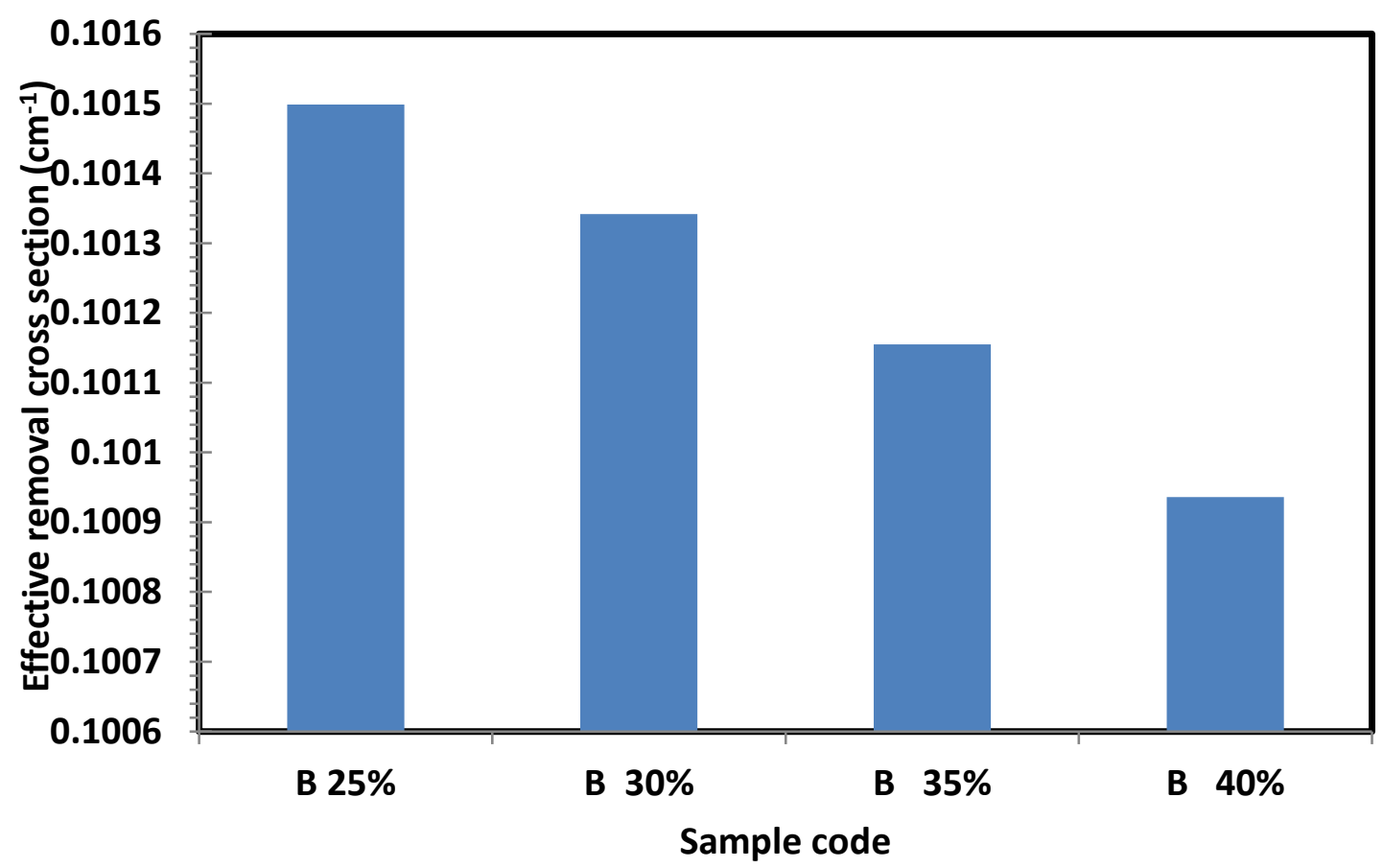

Fig.19: Fast neutron removal cross sections $\Sigma \mathrm{R}$ values for fabricated glass samples. 